\title{
Synthetic Approaches to Coronafacic Acid, Coronamic Acid, and Coronatine
}

\author{
Mairi M. Littleson ${ }^{a}$ \\ Claire J. Russell \\ Elizabeth C. Frye ${ }^{\text {b }}$ \\ Kenneth B. Ling ${ }^{\text {b }}$ \\ Craig Jamieson ${ }^{a}$ \\ Allan J. B. Watson*a \\ a Department of Pure and Applied Chemistry, WestCHEM, \\ University of Strathclyde, Thomas Graham Building, 295 \\ Cathedral Street, Glasgow, G1 1XL, UK. \\ ${ }^{\mathrm{b}}$ Syngenta, International Research Centre, Jealott's Hill, \\ Bracknell, West Berkshire RG42 6EY. \\ *allan.watson.100@strath.ac.uk.
}

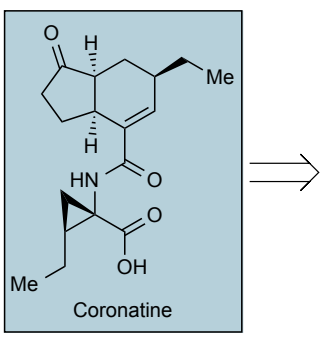

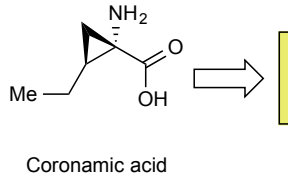

Total synthesis Methodology development Agrochemical discovery

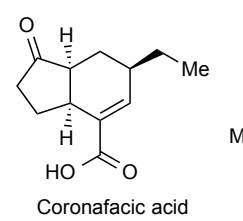

\section{Received: \\ Accepted: \\ Published online: \\ $\mathrm{DOI}$}

Abstract The phytotoxin coronatine (COR) is a functional mimic of the active plant hormone (+)-7-iso-jasmonoyl-L-isoleucine (JA-Ile), which regulates stress responses. Structurally, COR is composed of a core unit, coronafacic acid (CFA), which is connected to coronamic acid (CMA), via an amide linkage. COR has been found to induce a range of biological activity in plants and based on its biological profile, COR, as well as CFA, and CMA are attractive starting points for agrochemical discovery, resulting in numerous total synthesis efforts. This review will discuss the synthetic approaches towards CFA, CMA and, ultimately COR, to date.

Key words Agrochemistry, asymmetric synthesis, bicyclic compounds, carbocycles, stereochemistry, total synthesis.

\section{Contents}

1. Introduction

2. Total synthesis of coronafacic acid (CFA, 4

2.1 Mapping synthetic strategies

2.2 Intermolecular Diels-Alder approaches

2.3 Intramolecular Diels-Alder approaches

2.4 Conjugate addition approaches

2.5 Haller-Bauer approaches

2.6 Intramolecular cyclisation approaches

2.7 Oxy-Cope approaches

3. Total synthesis of coronamic acid (CMA, 5 )

3.1 Mapping synthetic strategies

3.2 Final installation of $C_{1}$

3.2 Final installation of $\mathrm{C}_{2}$

3.3 Final installation of $\mathrm{C}_{3}$

4. Total synthesis of coronatine $(\mathrm{COR}, 1)$

5. Conclusions

Acknowledgement

References

Author biographies

\section{Introduction}

The phytotoxin coronatine (COR) 1, which was isolated from the bacteria Pseudomonas Syringae, ${ }^{1}$ has been a popular synthetic target since its structural elucidation in $1977.2^{2,3} \mathbf{1}$ has been found to be a functional mimic of the active plant hormone (+)7-iso-jasmonoyl- $L$-isoleucine (JA-IIe, 2) ${ }^{4}$, which regulates stress responses in plants (Figure 1). ${ }^{5}$ The jasmonate receptor is a three component, co-receptor complex consisting of the F-box protein COI1, the JAZ1 degron peptide, and inositol pentakisphosphate, where all three components are essential for normal activity. ${ }^{6}$ Jasmonic acid (3) is produced enzymatically from linolenic acid ${ }^{7}$ and is activated in plants by conjugation with $L$-isoleucine. ${ }^{8}$ The active hormone elicits ubiquitination and subsequent degradation of JAZ proteins, which leads to transcriptional activation of genes involved in plant development and defence..$^{9,4}$ Acting as a JA-lle agonist, $\mathbf{1}$ has been found to induce a range of biological responses in plants, including chlorosis, ${ }^{10,11}$ inhibition of root elongation, ${ }^{12}$ increased production of protease inhibitors, ${ }^{10}$ and growthregulator type activity, ${ }^{13}$ including enhanced ethylene production, ${ }^{14}$ induced hypertrophy, ${ }^{12}$ and tendril coiling. ${ }^{1}$

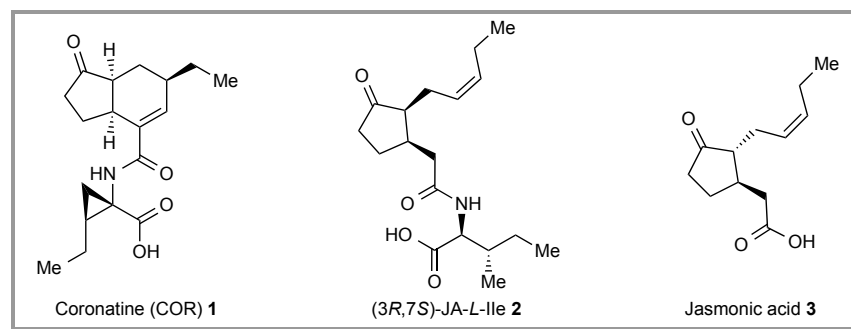

Figure 1 Coronatine (COR, 1), (+)-7-iso-jasmonoyl-L-isoleucine (JA-Ile, 2), and jasmonic acid (3).

Structurally, $\mathbf{1}$ is composed of a bicyclic core unit, coronafacic acid (CFA, 4) that is connected to coronamic acid (CMA, 5), a derivative of isoleucine, via an amide linkage (Figure 2).

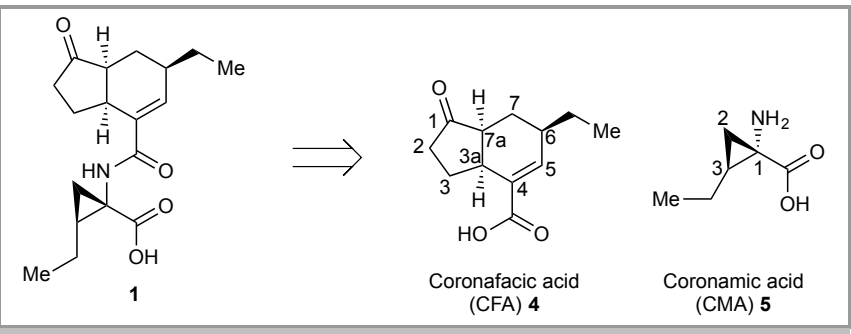

Figure 2 Coronatine (1), coronafacic acid (4), and coronamic acid (5).

Based on its biological activity, $\mathbf{1}$ and analogues have potential as starting points for agrochemical design, as demonstrated in several communications describing the biological evaluation of analogues of $\mathbf{1} .{ }^{15}$ Derivatives of both $\mathbf{1}$ and $\mathbf{3}$ have been used to generate structure-activity relationships (SAR) for herbicidal 
activity. ${ }^{15}$ In addition, there has been significant interest in the structurally simpler $\mathbf{1}$ mimic coronalon (6), ${ }^{16}$ and the oxime derivative of $\mathbf{1}$ (7), which has been reported to possess antagonist activity in the jasmonic acid signalling pathway (Figure 3).5 Lastly, $\mathbf{1}$ has been functionalized to allow its incorporation into biological probes, ${ }^{17,18}$ and, furthermore, antibodies have been developed for the quantification of $\mathbf{1}$ in competitive enzyme-linked immunosorbent assays (ELISAs). ${ }^{19}$

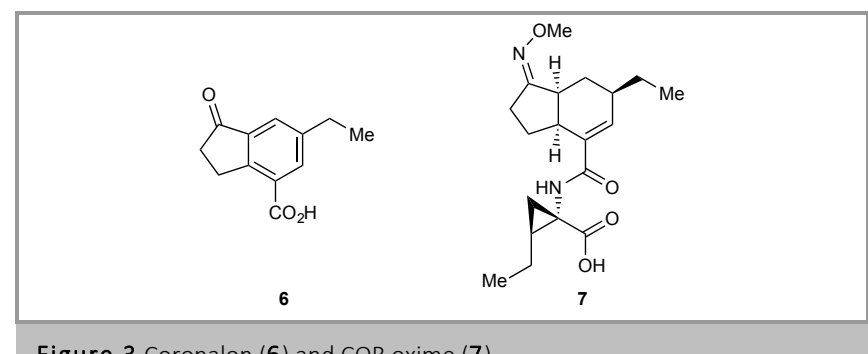

Figure 3 Coronalon (6) and COR oxime (7).

Through the efforts of various research groups, there is an emerging SAR associated with $\mathbf{1}$. The cis-ring junction of $\mathbf{4}$ is also observed in $\mathbf{2}$, and is important for biological activity, ${ }^{20}$ as is the position of the carboxyl moiety relative to the cyclopropane ring. ${ }^{21}$ Variation of the amino acid portion of $\mathbf{1}$ (i.e., $\mathbf{5}$ ) is tolerated ${ }^{21}$ while the ethyl unit of $\mathbf{4}$ is not crucial for biological activity. ${ }^{21}$ However, despite significant interest in $\mathbf{1}$ as a starting point for agrochemical development, current synthetic routes do not allow flexible access to $\mathbf{1}$ in sufficient quantities or with embedded useful functionality for analogue generation. ${ }^{20}$ Overall, based on the above, efficient methodology giving synthetic access to $\mathbf{1}$ and analogues would be advantageous to allow interrogation of SAR and the potential development of more potent derivatives. ${ }^{20}$

In this review, we summarise and discuss the reported syntheses of $\mathbf{4}, \mathbf{5}$, and ultimately $\mathbf{1}$ in the literature to date, and provide an assessment of these routes in supporting further SAR work around this promising target.

\section{Total synthesis of coronafacic acid (CFA, 4)}

\subsection{Mapping synthetic strategies}

The popularity of $\mathbf{1}$ as a target can be seen from the total syntheses of its constituent natural products, $\mathbf{4}$ and $\mathbf{5}$. Numerous total syntheses of racemic $\mathbf{4}$ have been reported, along with several enantiopure preparations. Table 1 shows the reported syntheses of $\mathbf{4}$ in chronological order and grouped according to their associated key step; Figure 4 shows these key steps in more detail. Typically, synthetic routes towards $\mathbf{4}$ have been somewhat protracted and ultimately low yielding. The $\mathrm{C}_{6}$ ethyl unit must be installed trans-relative to the cis-ring junction of the bicycle, and this relationship must be preserved. Often mixtures of diastereoisomers are carried through several steps of the synthesis, resulting in difficult product isolation as well as issues with characterization. ${ }^{22}$

Synthetic strategies towards $\mathbf{4}$ can generally be grouped into five approaches based on the key transformation in the route: inter- and intramolecular Diels-Alder (DA) reaction, conjugate addition, Haller-Bauer reaction, intramolecular cyclization, and
oxy-Cope methodology. Each of these lynchpin strategies will be reviewed in the following sections.

\begin{tabular}{|c|c|c|c|c|}
\hline $\begin{array}{l}\text { Author } \\
\text { (Year) }\end{array}$ & $\begin{array}{c}\text { Key step } \\
\text { (No. steps) }\end{array}$ & $\begin{array}{c}\text { Racemic/ } \\
\text { enantiopure }\end{array}$ & $\begin{array}{c}\text { Overall } \\
\text { Yield (\%) }\end{array}$ & Ref. \\
\hline Ichihara (1977) & Diels-Alder $\left(10^{\mathrm{a}}\right)$ & Racemic & Unknown & 23 \\
\hline Ichihara (1980) & Diels-Alder $\left(14^{\mathrm{b}, \mathrm{c}}\right)$ & Racemic & 0.4 & 29 \\
\hline Jung (1981) & Diels-Alder $\left(8^{\mathrm{d}}\right)$ & Racemic & 7 & 31 \\
\hline $\begin{array}{c}\text { Llinas-Brunet } \\
\text { (1984) }\end{array}$ & Diels-Alder $\left(9^{\mathrm{a}}\right)$ & Racemic & 4 & 24 \\
\hline Yates (1990) & Diels-Alder $\left(12^{b}\right)$ & Racemic & 24 & 34 \\
\hline $\begin{array}{l}\text { Charette } \\
(2007)\end{array}$ & Diels-Alder $\left(6^{\mathrm{a}}\right)$ & Racemic & 29 & 32 \\
\hline Ueda (2009) & Diels-Alder $\left(12^{\mathrm{a}}\right)$ & Racemic & 5 & 26 \\
\hline Ueda (2010) & Diels-Alder $\left(8^{\mathrm{a}}\right)$ & Racemic & 28 & 17 \\
\hline Ichihara (1996) & $\begin{array}{c}\text { Conjugate } \\
\text { addition }\left(7^{\mathrm{a}}\right)\end{array}$ & Racemic & 25 & 35 \\
\hline Ichihara (1997) & $\begin{array}{c}\text { Conjugate } \\
\text { addition }\left(9^{b}\right)\end{array}$ & Enantiopure & 24 & 36 \\
\hline $\begin{array}{c}\text { Shibasaki } \\
\text { (1998) }\end{array}$ & $\begin{array}{c}\text { Conjugate } \\
\text { addition }\left(6^{e}\right)\end{array}$ & Enantiopure & $9^{f}$ & 37 \\
\hline Mehta (1993) & Haller-Bauer $\left(8^{\mathrm{a}}\right)$ & Racemic & 11 & 40 \\
\hline Mehta (1999) & Haller-Bauer $\left(12^{\mathrm{a}}\right)$ & Enantiopure & 5 & 43 \\
\hline Tori (2000) & $\begin{array}{l}\text { Intramolecular } \\
\text { cyclisation }\left(18^{\mathrm{d}}\right)\end{array}$ & Racemic & 0.9 & 45 \\
\hline Tsuji (1981) & $\begin{array}{l}\text { Intramolecular } \\
\text { cyclisation }\left(15^{a}\right)\end{array}$ & Racemic & Unknown & 46 \\
\hline $\begin{array}{c}\text { Nakayama } \\
\text { (1981) }\end{array}$ & $\begin{array}{l}\text { Intramolecular } \\
\text { cyclisation }\left(12^{\mathrm{b}}\right)\end{array}$ & Racemic & 0.9 & 49 \\
\hline $\begin{array}{c}\text { Nakayama } \\
\text { (1983) }\end{array}$ & $\begin{array}{l}\text { Intramolecular } \\
\text { cyclisation }\left(12^{a}\right)\end{array}$ & Enantiopure & 0.1 & 53 \\
\hline Blechert (1996) & $\begin{array}{l}\text { Intramolecular } \\
\text { cyclisation }\left(9^{\text {b }}\right)\end{array}$ & Racemic & 16 & 47 \\
\hline Taber (2009) & $\begin{array}{l}\text { Intramolecular } \\
\text { cyclisation }\left(12^{\mathrm{a}}\right)\end{array}$ & Enantiopure & 4 & 57 \\
\hline $\begin{array}{c}\text { Kobayashi } \\
\text { (2011) }\end{array}$ & $\begin{array}{l}\text { Intramolecular } \\
\text { cyclisation }\left(12^{\mathrm{a}, \mathrm{c}}\right)\end{array}$ & Enantiopure & 15 & 22 \\
\hline $\begin{array}{c}\text { Kobayashi } \\
\text { (2013) }\end{array}$ & $\begin{array}{l}\text { Intramolecular } \\
\text { cyclisation }\left(11^{\mathrm{a}, \mathrm{c}}\right)\end{array}$ & Enantiopure & 1.6 & 56 \\
\hline Jung (1980) & oxy-Cope $\left(14^{\mathrm{a}}\right)$ & Racemic & 1.7 & 60 \\
\hline
\end{tabular}

${ }^{a}$ From a non-commercial starting material. ${ }^{b}$ From commercial starting materials. ${ }^{c}$ Based on longest linear sequence. ${ }^{d}$ Starting material commercial but not readily accessible. ${ }^{e}$ A required catalyst is not commercial. ${ }^{f}$ Based on an assumed yield from referenced publication. 


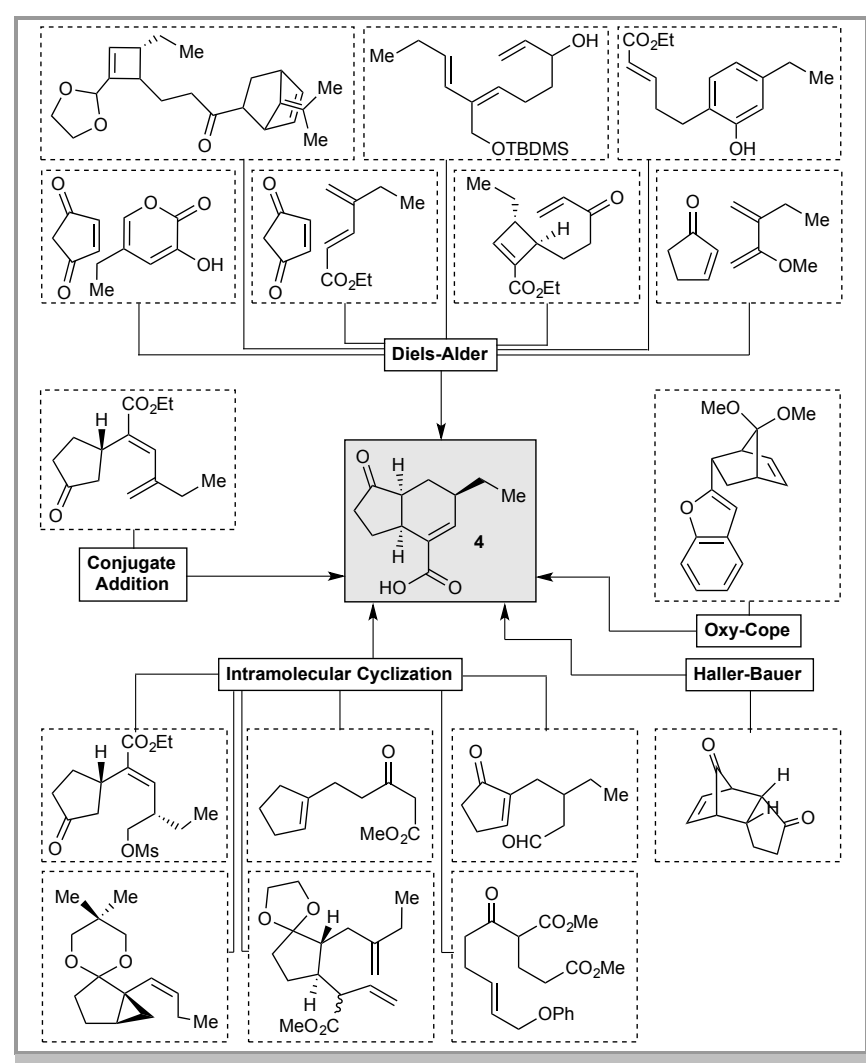

Figure 4 Overview of the key steps towards CFA.

\subsection{Intermolecular Diels-Alder approaches}

The presence of the cyclohexene-derived core within $\mathbf{4}$ has rendered the Diels-Alder reaction a common key disconnection. In 1977, Ichihara reported the first synthesis of ( \pm )-4 via an intermolecular Diels-Alder reaction. ${ }^{23}$ Despite requiring harsh conditions and proceeding in only moderate yield, the reaction provided access to bicycle 10, as a 1:1 mixture of diastereomers, containing the desired cis-ring junction (Scheme 1).23

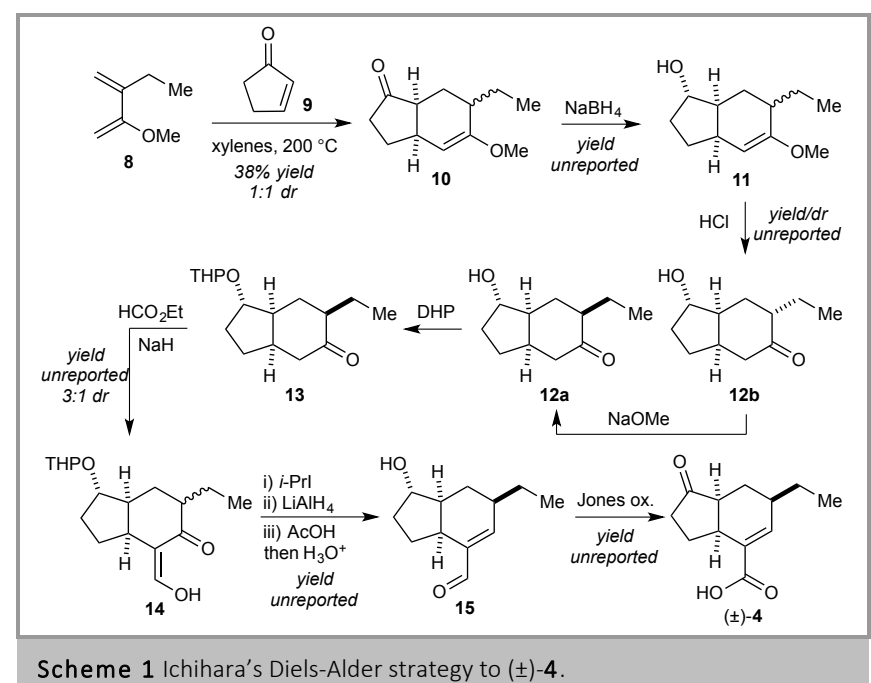

Despite having accessed the complete carbon framework, a further nine transformations, for which yields were not communicated, were required to deliver $( \pm)-\mathbf{4}$.
Reduction of the cyclopentanone (10) from the convex face gave alcohol 11. Subsequent hydrolysis of the enol ether afforded $\mathbf{1 2}$ as a mixture of diastereomers at $\mathrm{C}_{6}$, for which the ratio was not communicated. 12a, bearing the desired relative stereochemistry, was found to be the more stable isomer, and the undesired isomer $\mathbf{1 2 b}$ could be epimerized to 12a upon treatment with base. THP protection was followed by formation of the formylated compound 14, which was converted to $\mathbf{1 5}$ by alcohol protection, ketone reduction, and subsequent acidmediated dehydration. Deprotection to alcohol $\mathbf{1 5}$ and a final Jones oxidation afforded the first example of synthetic ( \pm ) $-\mathbf{4}$. Given the lack of yield information, it is difficult to comment further on the utility of this process for rapid analogue generation. If sufficient quantities of $( \pm)-\mathbf{4}$ can be obtained, this could facilitate evaluation of CMA replacements.

Using an alternative intermolecular Diels-Alder reaction, ( \pm )-4 was synthesized by Llinas-Brunet et al, again allowing the complete carbon framework to be rapidly assembled (Scheme 2). ${ }^{24}$

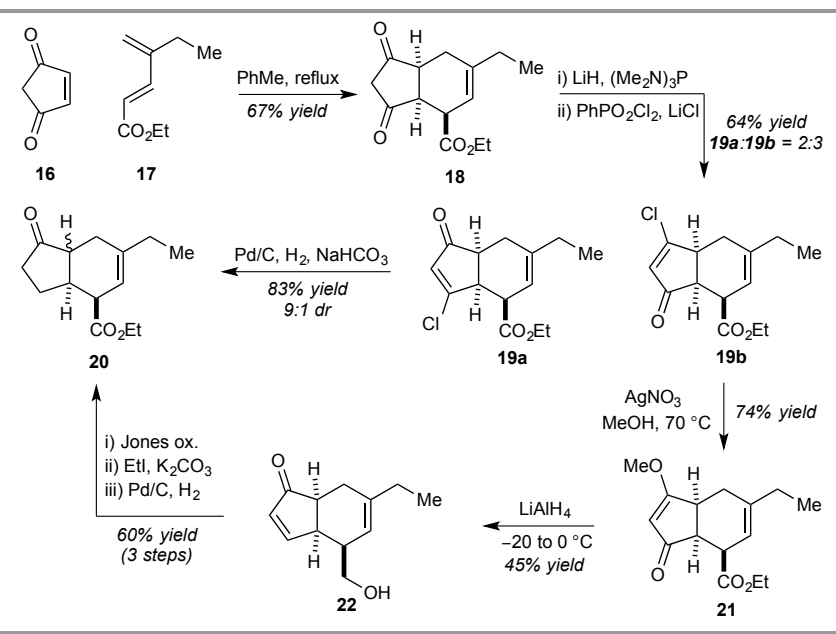

Scheme 2 Llinas-Brunet's Diels-Alder strategy to $( \pm)-4$.

Heating cyclopentendione $\mathbf{1 6}$ with diene $\mathbf{1 7}^{25}$ in PhMe smoothly afforded bicycle 18, which could be advanced to 4 in eight steps. Chlorination using phenyldichlorophosphate gave a mixture of regioisomers 19a and $19 \mathrm{~b}$ in a ratio of $2: 3$, respectively. With respect to analogue generation, these intermediates are potentially useful for SAR development around the cyclopentane ring of 4 based on the synthetic utility of the chloroenone. 19a was converted to bicycle $\mathbf{2 0}$ in one step via chemoselective hydrogenation, as a mixture of diastereomers at $\mathrm{C}_{7 \mathrm{a}}$. Despite this, conversion of $\mathbf{1 9 b}$ to 20 required a multistep procedure: treatment with $\mathrm{AgNO}_{3}$ in $\mathrm{MeOH}$ afforded 21. $\mathrm{LiAlH}_{4}$ reduction delivered enone 22, which was converted to $\mathbf{2 0}$ via Jones oxidation, esterification, and chemoselective hydrogenation of the enone alkene. 20 was treated with NaOEt to bring the $\mathrm{C}_{5}-\mathrm{C}_{6}$ double bond into conjugation with the ester and acid-mediated hydrolysis of the ester, which afforded ( \pm )-4 with the desired relative stereochemistry $(52 \%$ yield over two steps (not shown)). This synthetic route was used to prepare $11 \mathrm{mg}( \pm)-\mathbf{4}$, which is insufficient for further SAR development; however, the route may be amenable to scale up.

A similar Diels-Alder reaction approach was communicated by Ueda et al (Scheme 3). ${ }^{26}$ Functionalized hydroxypyrone 23 was 
accessed in four steps from commercial materials, ${ }^{27}$ which adds to the synthetic complexity of the route. The Diels-Alder reaction of $16^{24}$ and 23 gave access to bridged tricycle 24 in high yield and with moderate exo-selectivity, rationalised due to a greater stability of the exo-transition state, resulting from steric clashes incurred in the endo-model. ${ }^{26}$

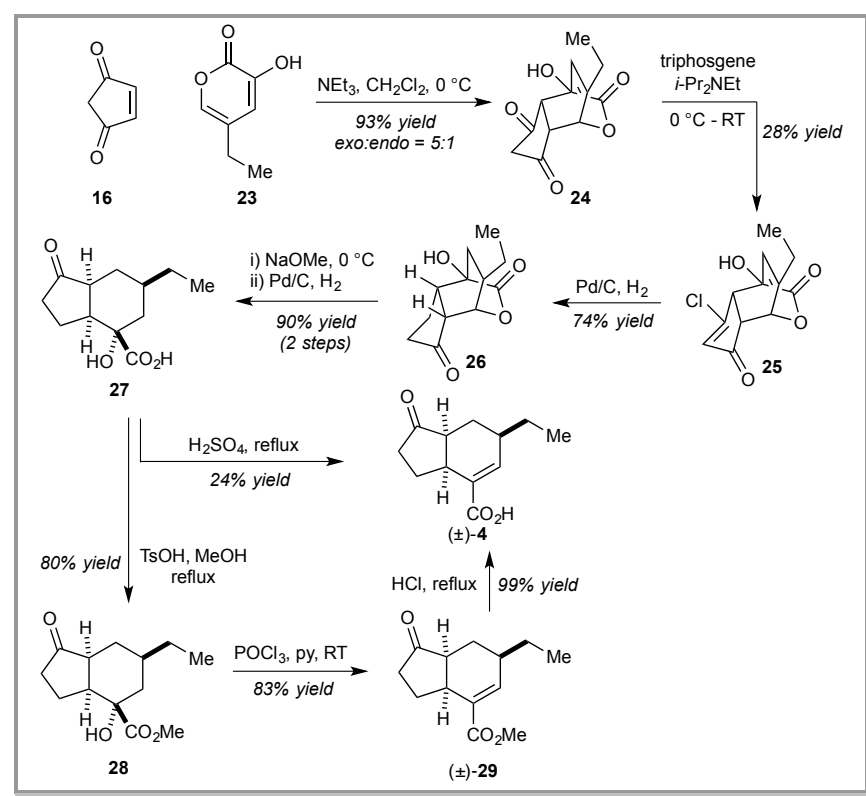

Scheme 3 Ueda's Diels-Alder strategy to $( \pm)-4$

Intermediate $\mathbf{2 4}$ was then converted to $( \pm)-\mathbf{4}$ in seven steps. Removal of the $C_{3}$ carbonyl was achieved using a two-step procedure similar to the Llinas-Brunet ${ }^{24}$ approach: chlorination using triphosgene provided chloroenone 25, which was hydrogenated to afford ketone $\mathbf{2 6}$. Sodium methoxide-mediated elimination of the carboxylate and subsequent hydrogenation of the resulting enone alkene gave intermediate $\mathbf{2 7}$ in $90 \%$ yield over two steps. Methyl ester formation (28) was followed by dehydration to give $\mathbf{2 9}$, which was then hydrolyzed to $( \pm)-4$. The authors reported that the last three synthetic steps could be replaced by a single step in which 27 was refluxed in $\mathrm{H}_{2} \mathrm{SO}_{4}$. While requiring fewer steps, the overall yield from 27 using this approach was found to be significantly lower (24\% vs. 66\%). Ueda used this synthetic sequence to prepare $65 \mathrm{mg}( \pm)-\mathbf{4}$, suggesting this route could potentially be used to access useful quantities of CFA for analogue development.

Following this initial synthesis, Ueda reported an improvement of their synthetic sequence, ${ }^{17}$ giving access to intermediate $\mathbf{2 6}$ in an improved step count and associated yield (Scheme 4). ${ }^{26}$

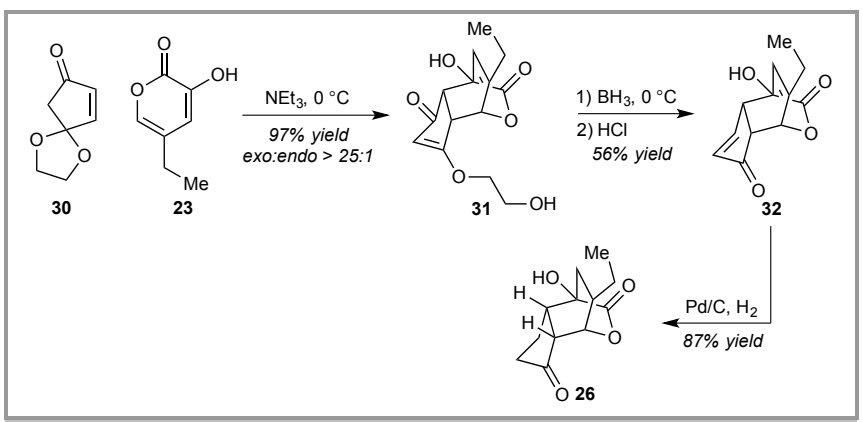

Scheme 4 Ueda's improved strategy to intermediate 26
Notably, the associated key Diels-Alder reaction using the monoketal derivative of $\mathbf{1 6}(\mathbf{3 0})^{28}$ was considerably more selective. Reduction and subsequent acid-mediated hydrolysis/elimination delivered 32, which underwent hydrogenation to rapidly deliver the advanced intermediate $\mathbf{2 6}$. Significantly, the $( \pm)-\mathbf{4}$ prepared using this route was then used in the synthesis of a biological probe, ${ }^{17}$ illustrating the potential of this route to deliver sufficient quantities of $( \pm)-\mathbf{4}$ for further study.

\subsection{Intramolecular Diels-Alder approaches}

Intramolecular Diels-Alder reactions have been used frequently as a strategy towards $( \pm)-4$. The majority of these approaches have focused on the generation of the triene intermediate $\mathbf{3 3}$ and related derivatives (Figure 5). The Diels-Alder reaction of 33 has been found to be exo-selective, resulting in the pharmacologically undesired trans ring junction. However, the stereochemistry at $\mathrm{C}_{7 \mathrm{a}}$ of $\mathbf{3 4 a}$ is readily epimerised to give the desired cis diastereoisomer. ${ }^{29}$

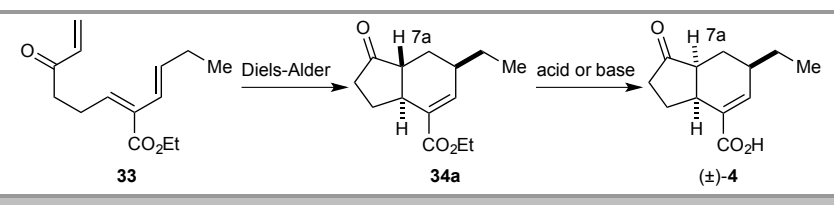

Scheme 5 Intramolecular Diels-Alder reaction of key triene 33.

Ichihara reported the first intramolecular Diels-Alder reaction strategy towards ( \pm )-4 in 1980, utilizing a late stage conrotatory ring opening, followed by a retro-Diels Alder reaction to give access to the desired triene, and, finally, a Diels-Alder reaction in a one-pot procedure to afford bicycle 37 in $92 \%$ yield (Scheme 6). 29

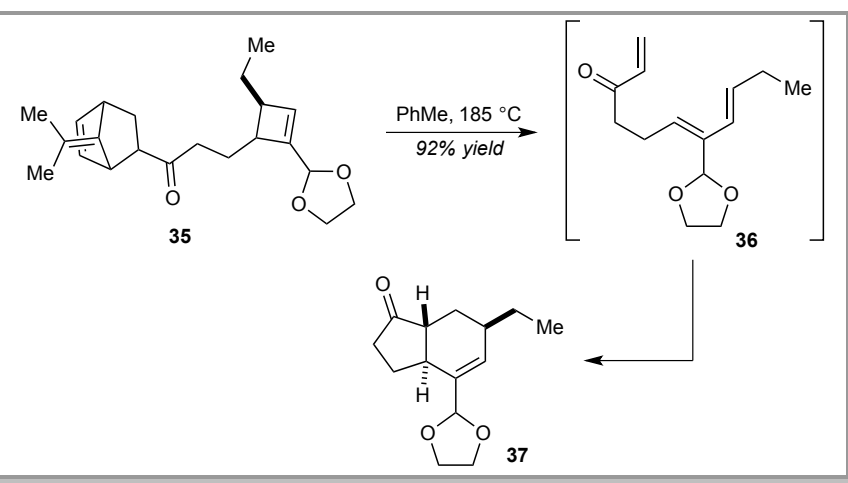

Scheme 6 Ichihara's cascade Diels-Alder strategy to ( \pm )-4

While providing 37 very rapidly and in high yield, formation of intermediate $\mathbf{3 5}$ required twelve steps, albeit from simple starting materials, ${ }^{29,30}$ which limits the utility of the route to access sufficient quantities of $( \pm)-\mathbf{4}$ for analogue generation. The required reactive diene and dienophile were masked by thermally labile protecting groups throughout these steps. Acetal intermediate $\mathbf{3 7}$ was isolated with the expected trans ring junction and was isomerized to the cis isomer using $\mathrm{NaOMe}$. ( \pm )-4 was then quickly accessed from 37 by one-pot acetal deprotection/Jones oxidation, proceeding in $22 \%$ yield (not shown). 
A similar conrotatory ring opening approach to unmask a reactive diene for intramolecular Diels-Alder reaction has been communicated by Jung et al (Scheme 7). ${ }^{31}$

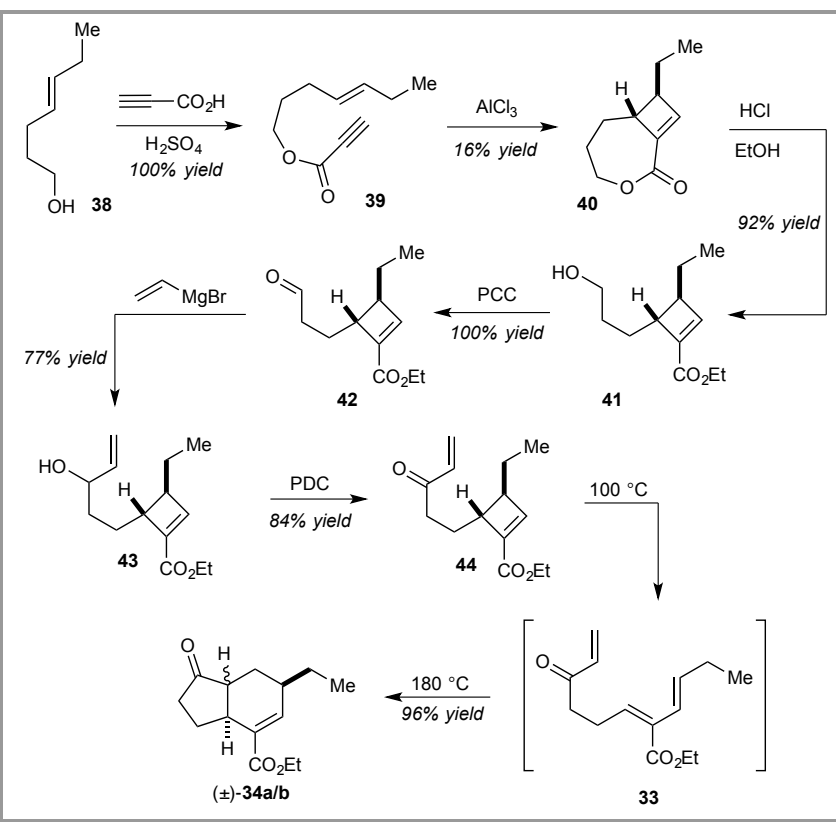

Scheme 7 Jung's cascade Diels-Alder reaction strategy to $( \pm)-4$.

An intramolecular $(2+2)$ cycloaddition of ynoate 39 generated cyclobutene $\mathbf{4 0}$ and established the desired stereochemistry at $\mathrm{C}_{3}$ and $\mathrm{C}_{4}{ }^{31}$ Despite optimization, this transformation was limited to $16 \%$ yield but with significant recovered starting material. This low yielding step early in the synthetic route limits the utility of the sequence with respect to the preparation of significant quantities of $( \pm)$-4. A series of simple, high yielding steps then gave access to key intermediate 44: acid-mediated ester hydrolysis was followed by PCC oxidation, addition of vinylmagnesium bromide, and a second oxidation. Thermolysis of $\mathbf{4 4}$ generated triene $\mathbf{3 3}$ in situ, which, on increasing the temperature, underwent the expected Diels-Alder reaction to deliver 34a/b in high yield and in approximately 60:40 ratio in favour of the desired cis isomer $\mathbf{3 4 \mathbf { b }}$. This mixture was converted to ( \pm )-4 in a single step by ester hydrolysis with concomitant epimerisation of the ring junction to the cis isomer (not shown). The authors also demonstrated that $( \pm$ )-4 could be accessed in nine steps with an overall yield of $7 \%$ when telescoped without purification of the intermediates.

In 2007 , the utility of species related to triene $\mathbf{3 3}$ as a precursor to ( \pm )-4 was again demonstrated by Charette et al (Scheme 8)..$^{32}$ In this example, the triene precursor was formed via diastereoselective boron-mediated aldol reaction of ester 45 with aldehyde $\mathbf{4 6}$ to deliver aldol products $\mathbf{4 7 a / 4 7 b}$ in a 87:13 anti:syn ratio. This aldol reaction was significant since these reaction conditions typically favour the cis enolate and, accordingly, the syn aldol product. ${ }^{33}$ However, the authors found that while $\alpha$-branched aldehydes gave the expected syn product, linear aldehydes gave the anti product predominantly. Significantly, 47a and $\mathbf{4 7 b}$ were readily separated by flash chromatography and, in a convergent strategy, each could be independently and selective dehydrated to afford the desired triene $\mathbf{4 8}$.
The authors demonstrated that $\mathbf{4 8}$ could be advanced to $\mathbf{3 3}$, via acetate hydrolysis and oxidation, and ultimately to $\mathbf{3 4 a / b}$ through the known Diels-Alder reaction approach (not shown). However, they developed an alternative Diels-Alder reaction in which both esters were reduced to give the corresponding diol 49, and then the primary alcohol selectively protected as the TBDMS ether 50. Oxidation of $\mathbf{5 0}$ to enone $\mathbf{5 1}$ enabled a thermal Diels-Alder reaction to give $\mathbf{5 2}$ in low yield of $24 \%$, proposed to be the result of decomposition of triene $\mathbf{5 1}$ occurring at the lower temperature than the desired cyclization. This yield could be improved to $61 \%$ by simply heating $\mathbf{5 0}$ in the presence of PDC, allowing for oxidation and Diels-Alder reaction in one pot. While the trans bicycle product would be expected, the authors found that epimerization of $\mathrm{C}_{7}$ a occurred during flash chromatography on silica gel to provide the cis product $\mathbf{5 2}$. Treatment of $\mathbf{5 2}$ with TBAF and a subsequent Jones oxidation completed a concise synthesis of $( \pm)$-4. It should be noted, however, that aldehyde $\mathbf{4 6}$ is not commercially available and required six steps to prepare, ultimately adding to the length of the overall synthesis and limiting the prospect for analogue generation via this route.

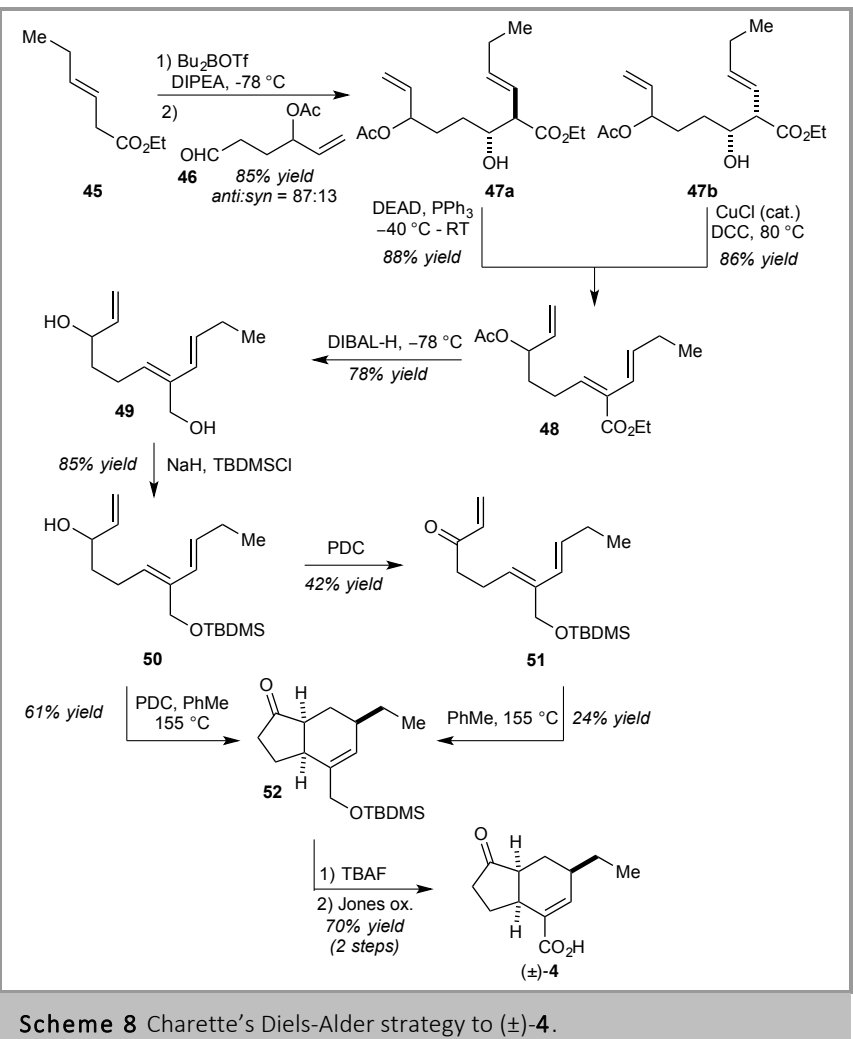

An alternative intramolecular Diels-Alder reaction was favoured by Yates et al who demonstrated the utility of their tandem Wessely oxidation/Diels-Alder reaction methodology towards ( \pm )-4 (Scheme 9). ${ }^{34}$ 


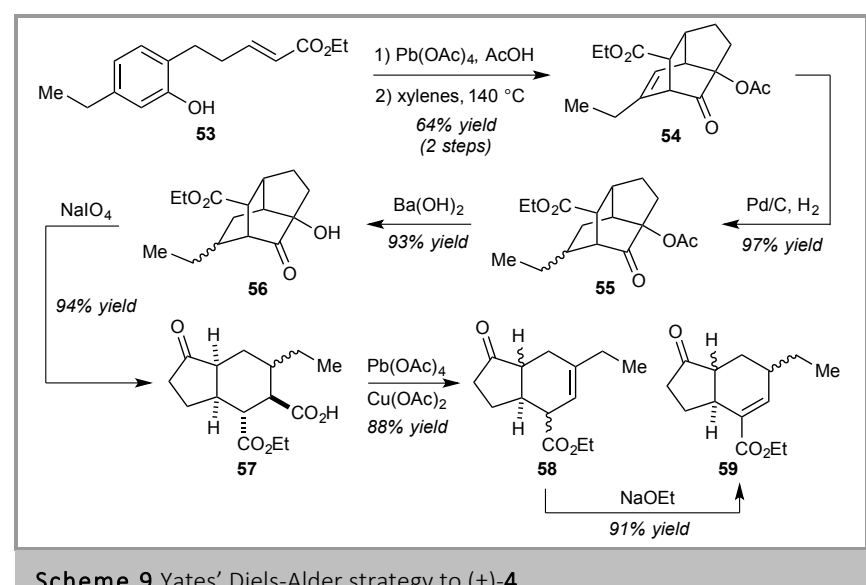

Scheme 9 Yates' Diels-Alder strategy to ( \pm )- 4 .

Intermediate phenol 53, which was synthesized in four high yielding steps from commercially available starting materials, underwent oxidation with $\mathrm{Pb}(\mathrm{OAc})_{4}$ to furnish the quinone derivative, followed by a thermal Diels-Alder reaction to give isotwistanone $\mathbf{5 4} .^{34}$ Hydrogenation afforded $\mathbf{5 5}$ as a mixture of diastereomers before acetate hydrolysis to give $\mathbf{5 6}$. Oxidative ring opening then gave the key bicyclic structure $\mathbf{5 7}$, as a mixture of diastereomers at $\mathrm{C}_{6} . \mathrm{Pb}(\mathrm{OAc})_{4} / \mathrm{Cu}(\mathrm{OAc})_{2}$-mediated oxidative decarboxylation gave access to $\mathbf{5 8}$ with olefinic isomer 59. However, $\mathbf{5 8}$ could be converted to $\mathbf{5 9}$ upon treatment with NaOEt. A final hydrolysis of $\mathbf{5 9}$ using aqueous acid afforded ( \pm )4 (not shown), with the correct cis ring junction, in $87 \%$ yield following several recrystallizations. Despite this synthetic approach being high yielding overall (24\%), the use of metalmediated transformations at several steps throughout the route, in particular the use of $\mathrm{Pb}(\mathrm{OAc})_{4}$, may limit its attractiveness with regard to scale up procedures.

\subsection{Conjugate addition approaches}

Annulation via conjugate addition as a route to both (+)-4 and $( \pm)-4$ has also been thoroughly explored. Again, the main objective in this approach is the setting of the cis-ring junction, relative to the trans-ethyl unit. Ichihara et al applied their conjugate addition based approach towards hydrindane scaffolds to the synthesis of $\left( \pm\right.$ )-4 (Scheme 10). ${ }^{35}$

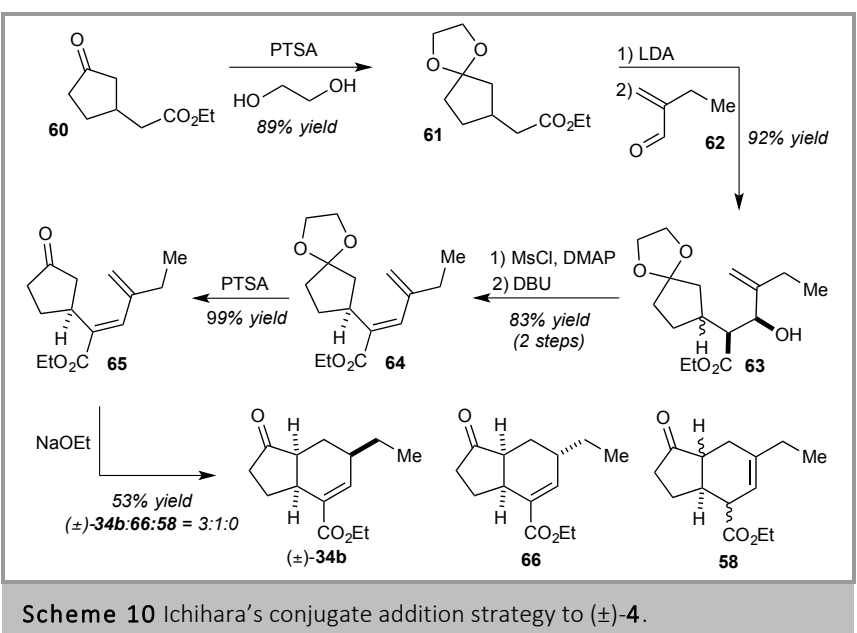

Protection of ketone $\mathbf{6 0}$ as the ketal gave intermediate $\mathbf{6 1}$, which took part in an aldol reaction with aldehyde 62 to give the syn adduct 63. The authors carried out this synthetic sequence using four differently substituted aldehydes, demonstrating the potential of this methodology to synthesize analogues of ( \pm )-4. Mesylate formation and subsequent basemediated elimination gave access to dienoate $\mathbf{6 4}$ as the sole product, which was deprotected to give the key cyclization precursor 65. Following optimization, it was found that judicious choice of reaction conditions allowed $\mathbf{6 5}$ to undergo an intramolecular 1,6-addition to afford $\mathbf{3 4 b}$ as the main product, albeit in moderate overall yield.

The authors reasoned that the desired product was formed from kinetic protonation of the cyclopentanone enolate. Under the reaction conditions, the stereochemical integrity of $\mathbf{3 4 b}$ was found to erode over time to deliver increased quantities of diastereoisomers 66 and 58. Finally, $( \pm)-4$ was obtained in $70 \%$ yield by acidic hydrolysis of $\mathbf{3 4 b}$ (not shown). This approach provided efficient access to $( \pm)-4$, requiring only seven steps from 60 and giving an overall yield of $25 \%$ - a significant improvement over previous syntheses. The scalability of this route was not commented on in the text; 35 however, the efficiency of the route to access $( \pm)-4$ certainly renders it attractive with respect to potential scale-up and subsequent analogue generation for SAR scanning.

The authors subsequently reported an asymmetric synthesis of (+)-4 by exploiting the same synthetic route using enantioenriched 68 (Scheme 11). ${ }^{36}$

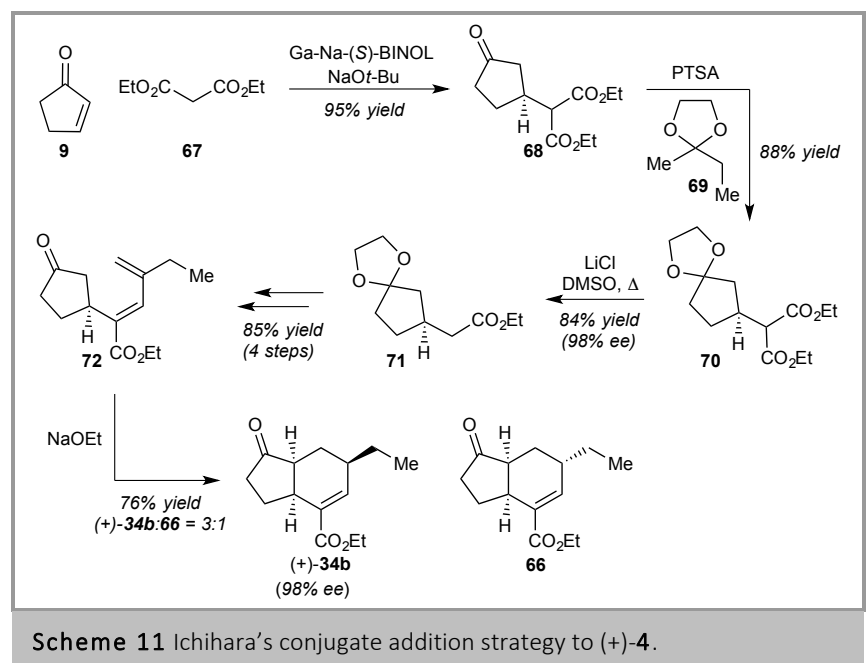

A catalytic asymmetric Michael addition of diethylmalonate $\mathbf{6 7}$ to cyclopentenone $\mathbf{9}$ delivered $\mathbf{6 8}$, which was protected as the ketal and subjected to Krapcho decarboxylation to provide $\mathbf{7 1}$ in $70 \%$ yield and $98 \%$ ee over three steps. Total synthesis of (+)-4 followed the previously described strategy, ${ }^{35}$ with the key intramolecular conjugate addition proceeding in an improved yield and product ratio. Enantioenriched (+)-4 was then prepared by ester hydrolysis (not shown) and in overall yield of $24 \%$ and in only nine steps from 9 . The authors comment that the relatively high overall yield of the synthetic route make it possible to gain access to practical quantities of $(+)-4$, and subsequently (+)-1.

In a later communication, Shibasaki et $a l^{37}$ used Ichihara's approach $^{35}$ to demonstrate the utility of their chiral aluminium catalyst in a similar asymmetric conjugate addition of 
triethylphosphonoacetate using an aluminium lithium bis(binaphthoxide) complex (ALB) to access phosphonate $\mathbf{7 3}$ (Scheme 12). ${ }^{38}$

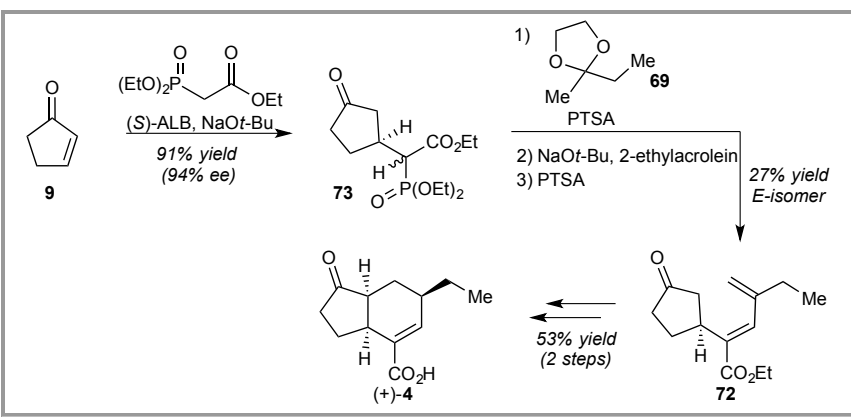

Scheme 12 Shibasaki's conjugate addition strategy to (+)-4.

The 1,4-addition proceeded in high yield and high ee; however, desired $E$-isomer was the minor product formed in the subsequent Horner-Wadsworth-Emmons reaction, which gave the $Z$-isomer preferentially in $43 \%$ yield. Following Ichihara's procedure, ${ }^{35}$ diene $\mathbf{7 2}$ was then converted to $(+)-\mathbf{4}$.

\subsection{Haller-Bauer approaches}

The Haller-Bauer reaction ${ }^{39}$ has also featured in CFA synthesis. Mehta et al applied the Haller-Bauer reaction to access cishydrindane scaffolds for the synthesis of $( \pm$ )-4 (Scheme 13).40-42

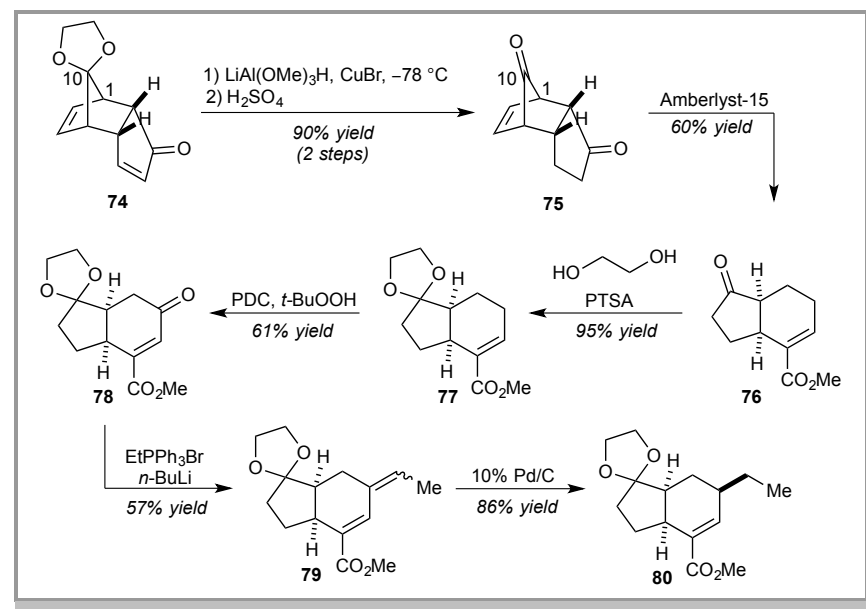

Scheme 13 Mehta's Haller-Bauer strategy to ( \pm )-4

Compound $\mathbf{7 4}$ was prepared following the three-step procedure of Chapman in $43 \%$ yield. ${ }^{41}$ Reduction and deprotection of $\mathbf{7 4}$ delivered 75, which underwent a Haller-Bauer reaction using Amberlyst resin to give bicycle 76. The regioselectivity of the Haller-Bauer reaction was found to be predictable, with cleavage occurring between $\mathrm{C}_{1}$ and $\mathrm{C}_{10}$. The double bond was found to migrate into conjugation with the ester functionality in situ and no $\mathrm{C}_{7 a}$ epimerization was observed. Following formation of acetal $\mathbf{7 7}$, allylic oxidation provided suitable carbonyl functionality at $\mathrm{C}_{6}$ (78) for a subsequent Wittig reaction to install the required ethyl unit (79). Substratecontrolled stereoselective hydrogenation from the convex face gave the desired stereochemistry of the ethyl substituent, with chemoselectivity over the enone, to provide $\mathbf{8 0}$. Acidic hydrolysis of the ketal and ester provided $( \pm)-4$ in $70 \%$ yield (not shown). The authors comment that this concise approach offers considerable potential for derivatization, highlighting that 74 can be accessed in multi-gram quantities. Mehta has also reported the enzymatic resolution of $\mathbf{7 4}$ using lipase PS, giving access to enantiopure (+)-4 following the same synthetic route (not shown).43,44

\subsection{Intramolecular cyclization approaches}

Intramolecular cyclization has been a popular strategy for assembly of the carbocyclic scaffold of $\mathbf{4}$. Tori et al applied a $\mathrm{SmI}_{2}$ - initiated radical cyclization towards the synthesis of $( \pm)-4$ (Scheme 14). 45

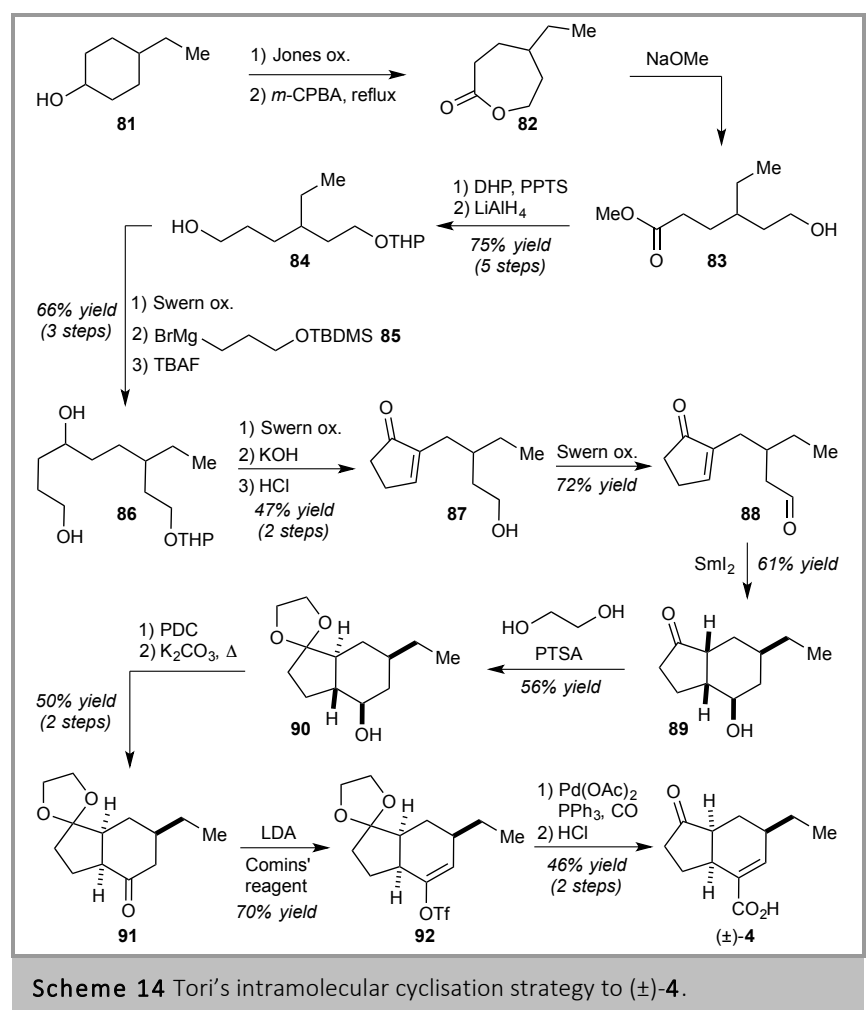

Commercially available alcohol $\mathbf{8 1}$ was oxidised to the corresponding ketone before Baeyer-Villiger oxidation to afford lactone 82. Treatment with $\mathrm{NaOMe}$ gave alcohol $\mathbf{8 3}$, which was protected before ester reduction provided alcohol $\mathbf{8 4}$ in good yield. Swern oxidation was followed by addition of Grignard $\mathbf{8 5}$, and TBAF deprotection to afford diol 86. Swern oxidation of both alcohols was followed by an intramolecular aldol condensation to afford cyclopentenone $\mathbf{8 7}$ in moderate yield. A final Swern oxidation gave access to the key intramolecular cyclization precursor, aldehyde $\mathbf{8 8}$. Exposing $\mathbf{8 8}$ to $\mathrm{SmI}_{2}$ initiated a 6-endo-trig cyclization, which delivered a mixture of four stereoisomers, where $\mathbf{8 9}$ was the major product. Following ketal formation, the secondary alcohol was oxidised, prior to base-mediated epimerization of $\mathrm{C}_{3 a}$ to the desired cis stereochemistry. Formation of triflate $\mathbf{9 2}$ and subsequent Pdcatalyzed carbonylation gave access to $( \pm)-\mathbf{4}$ after acid-mediated hydrolysis. The low overall yield obtained from this synthetic sequence $(0.9 \%)$ reduces the utility of the preparation with respect to generating practically useful quantities of $( \pm)-\mathbf{4}$. 
Pd-catalyzed allylic alkylation has also been used to good effect for ring construction towards the synthesis of ( \pm )-4. Tsuji demonstrated an intramolecular allylic alkylation cyclization protocol for the construction of the cyclopentanone ring (Scheme 15). ${ }^{46}$ It should be noted that precise details for this approach are limited, with many aspects of reaction conditions and outcomes not detailed in the report. $\beta$-Keto ester 93 underwent Michael addition with methyl acrylate to give diester 94. The key Pd-catalyzed intramolecular allylic alkylation was achieved using $\mathrm{Pd}(\mathrm{OAc})_{2}$ to afford the cyclopentanone product 95 in excellent yield. Decarboxylation and acetal formation was followed by alkylation to install the ethyl unit (97). Hydroboration, oxidation, and subsequent esterification gave 98. Protection through acetal formation preceded a Dieckmann condensation to form the 6-membered ring. Reduction of the cyclohexanone and hydrolysis of the ketal also provided the desired cis-ring junction. $\mathrm{POCl}_{3}$-mediated dehydration gave a mixture of $( \pm)-29$ and 101, with hydrolysis in acidic media delivering $( \pm)-4$.

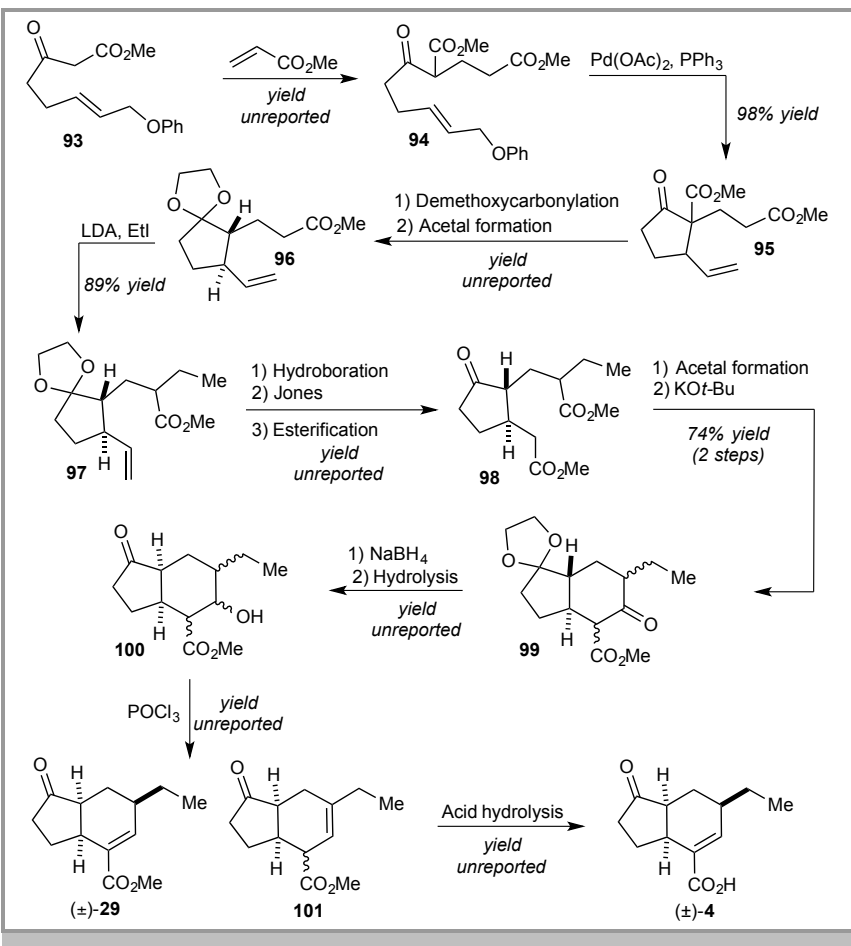

Scheme 15 Tsuji's allylic alkylation strategy to ( \pm )- 4 .

Again, the lack of detail communicated about the synthetic sequence does not allow comment on the synthetic utility of the route in regard to yields obtained or scalability of the process.

Ring closing metathesis (RCM) was used to construct the cyclohexene ring in Blechert's approach to $\left( \pm\right.$ )-4 (Scheme 16). ${ }^{47}$

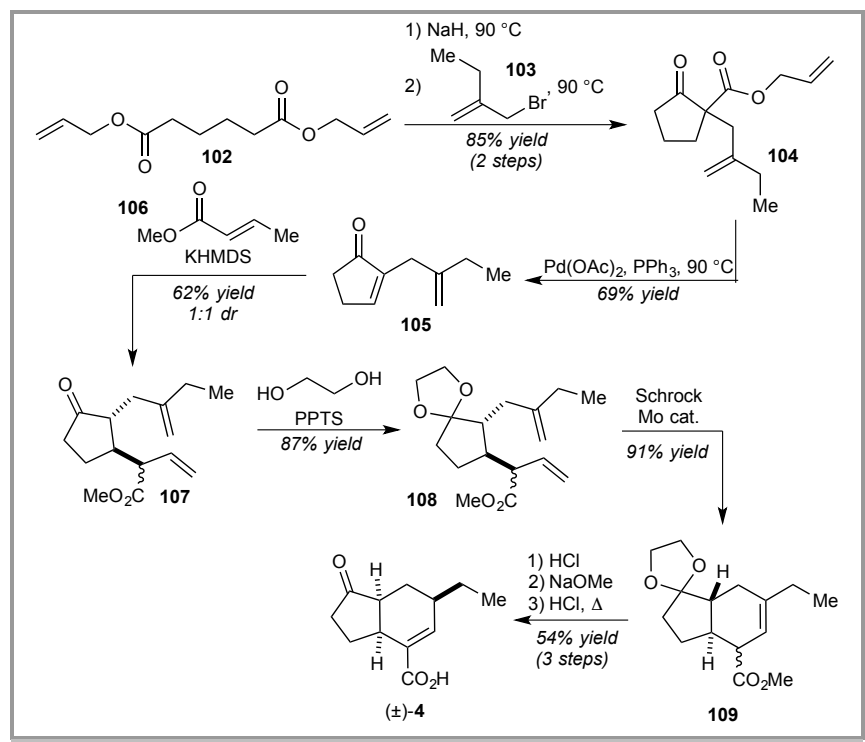

Scheme 16 Blechert's RCM strategy to ( \pm - -4 .

Commercially available diallyl adipate $\mathbf{1 0 2}$ underwent Dieckmann condensation, followed by alkylation with allyl bromide 103, and Pd-catalyzed decarboxylation to forge cyclopentenone 105.48 Michael addition of methyl crotonate then gave cyclization precursor $\mathbf{1 0 7}$ as a 1:1 mixture of diastereoisomers. Attempted RCM on $\mathbf{1 0 7}$ was met with little success, requiring high catalyst loading or elevated temperatures to ultimately afford the desired product in low yield. Protection of the ketone functionality as the ketal 108 allowed efficient RCM using Schrock's Mo catalyst to give access to bicycle 109. This key step was carried out on a $0.04 \mathrm{mmol}$ scale, and required the use of a glovebox, which reduces the practicality of the route and its applicability to scale up procedures. Ketal hydrolysis, base-mediated double bond isomerization, and acid-mediated hydrolysis/epimerization afforded ( \pm )-4.

Nakayama et al have reported a synthesis of ( \pm )-4 featuring an intramolecular [2+1] cycloaddition (Scheme 17). ${ }^{49}$ Starting from aldehyde 110, the cyclization precursor 112 was obtained in three steps. Reduction of the aldehyde, was followed by tosylation under phase transfer conditions, 50 and finally alkylation with methyl acetoacetate. Treatment of $\mathbf{1 1 2}$ with $p$ $\mathrm{TsN}_{3}$ afforded the corresponding diazo compound, which underwent thermal decomposition to afford the tricyclic intermediate 113. Introduction of the ethyl-unit was achieved through alkylation with excess ethyl iodide. The desired monoalkylated product $\mathbf{1 1 4}$ was obtained as a single stereoisomer as confirmed by X-ray crystallography; however, it was noted that the moderately low yield of $53 \%$ was obtained as a result of over alkylation to give the diethyl compound. Reduction with $\mathrm{NaBH}_{4}$ gave 115 as a mixture of epimers, both of which were submitted to tosylation and Grob fragmentation to give an inseparable mixture of methyl esters 116a and 116b. Treatment of this mixture with $\mathrm{NaBH}_{4}$ and dimethyl sulfate, 51 followed by oxidation with $\mathrm{H}_{2} \mathrm{O}_{2}$ and further oxidation with PCC, gave CFA methyl ester 29 in low yield from 116a. It was reported that $\mathbf{1 1 6} \mathrm{b}$ was resistant to the reaction conditions, and could be separated from the desired product. ( \pm )-4 was subsequently obtained in $80 \%$ yield by acid-mediated hydrolysis (not shown). 


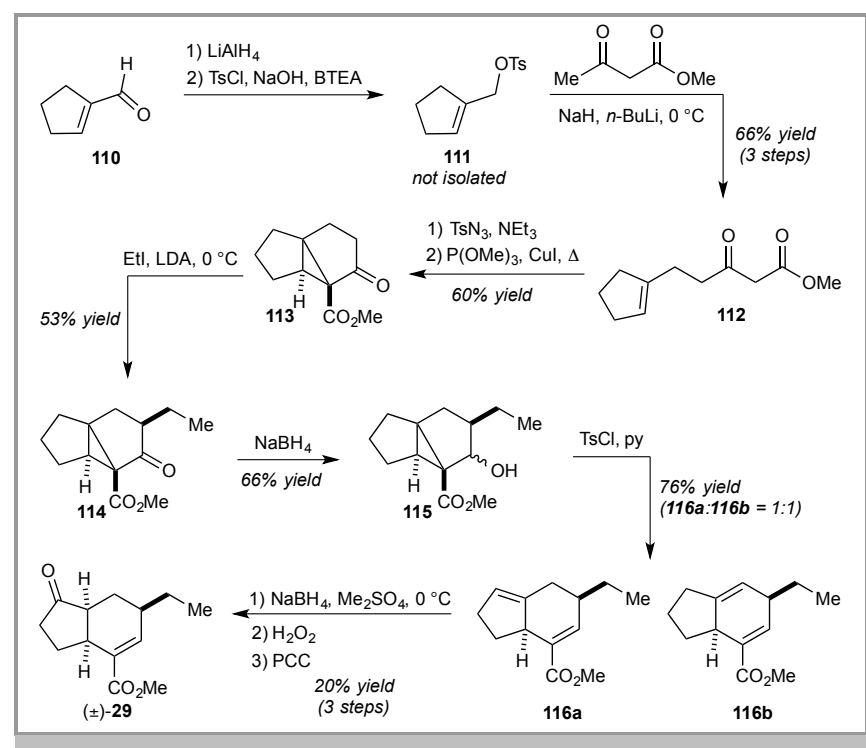

Scheme 17 Nakayama's $[2+1]$ cycloaddition approach to $( \pm)-4$.

The route was later modified by the Nakayama group to allow access to ( + - $\mathbf{4}$ by chromatographic separation through the use of l-menthyl esters (Scheme 18).52,53 The synthetic strategy focused on the separation of the l-menthyl ester derivatives 121a and 121b. Ester 117 was obtained by a known literature procedure, ${ }^{54}$ and the ethyl unit was introduced in high yield of $88 \%$ as a first step to avoid the problematic late stage alkylation seen in the groups original route to $( \pm)-4 .{ }^{49}$ Further alkylation gave $\beta$-keto ester 119 , which was cyclized in moderate yield of $56 \%$ using the previously communicated conditions. ${ }^{49}$ Cyclization afforded 120a and $\mathbf{1 2 0 b}$ as a mixture of $\mathrm{C}_{6}$-epimers, which could be converged to the desired 121a and 121b upon treatment with NaOMe. 121a and 121b could be separated by column chromatography and, following a final purification by recrystallization, were isolated in a 1:1 ratio.

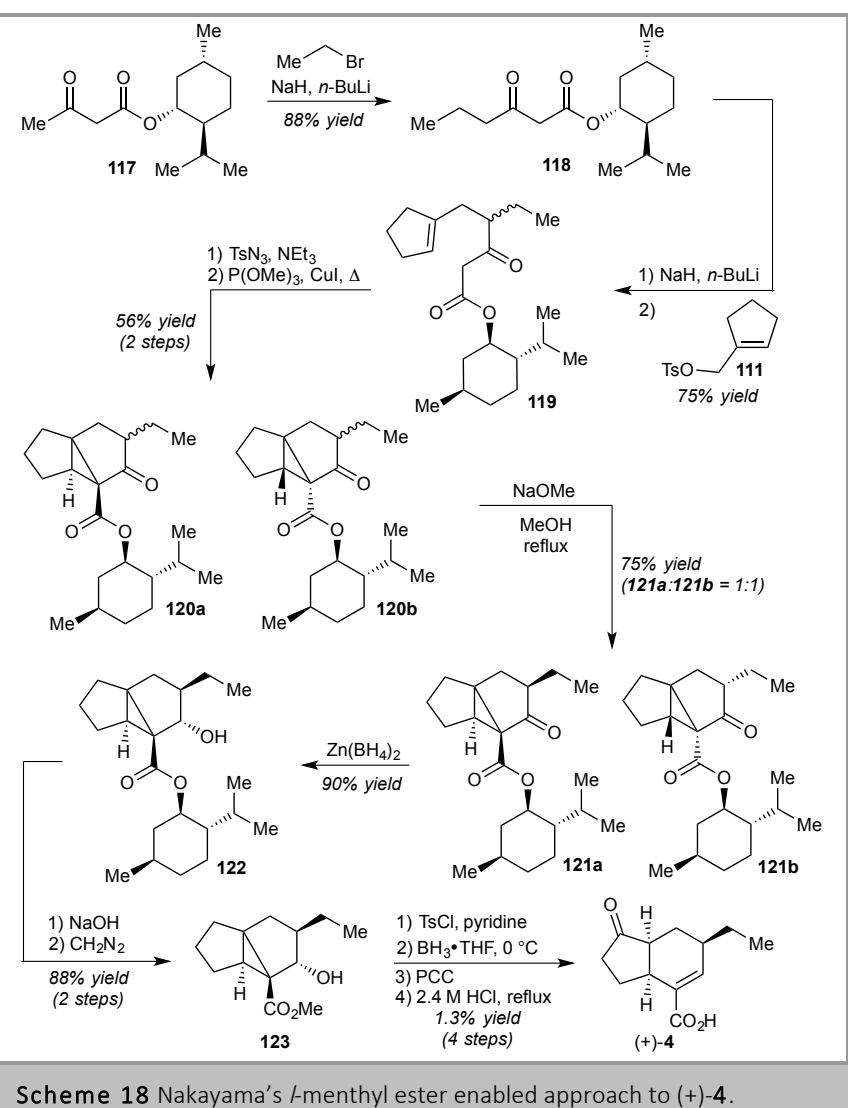

Reduction of $l$-menthyl ester 121a with $\mathrm{Zn}\left(\mathrm{BH}_{4}\right)_{2}$ afforded 122 as a single stereoisomer. The chiral auxiliary was then removed, giving methyl ester $\mathbf{1 2 3}$ in 88\% yield. Transformation of $\mathbf{1 2 3}$ to (+)-4 was achieved following the synthetic methodology developed in the same group's racemic synthesis, ${ }^{49}$ affording $(+)-4$ in $1.3 \%$ yield over four steps. The authors also demonstrated that 121b could be converted to (-)-4 (not shown). This approach was the first reported synthesis of both isomers of optically active 4 , which is attractive with respect to developing SAR for each enantioseries. ${ }^{53}$

Intramolecular cyclization has also been used in the synthesis of (+)-4 by Kobayashi et al (Scheme 19).22 Starting from enantiopure alcohol 124, which was readily prepared using literature methods, 55 TBS protected $\mathbf{1 2 5}$ underwent Pdcatalyzed allylic substitution with diethyl malonate. Decarboxylation afforded intermediate 127, which was then reacted under traditional base-mediated aldol reaction conditions to afford $\mathbf{1 2 9}$ as a mixture of four diastereomers. Aldehyde 128 was prepared by an $N$-acyl thiazolidinethione chiral auxillary-based literature method. ${ }^{55}$ The authors' synthetic strategy involved formation of intermediate 134, which bears structural similarity to conjugate addition precursor 72.35 Both synthetic routes involve mesylate formation and subsequent elimination; however, in this case the authors identified an unexpected TBAF-mediated elimination. Desilylation of $\mathbf{1 3 1}$ was expected, however, no desilylation took place and 132 was isolated in moderate yield; the authors hypothesized that elimination of the anti-isomer to afford the $Z$ alkene, was sterically disfavoured. Following ketone formation, base-mediated cyclization gave (+)-34b in moderate yield, allowing late stage formation of the cis-ring juncture. Unlike the conjugate addition-based approaches, the stereochemistry of 
the ethyl group was fixed at this point, which allowed the isolation of $(+)-\mathbf{3 4 b}$ as a single diastereomer. Acid hydrolysis gave access to $(+)-4$ in $85 \%$ yield (not shown). The authors then demonstrated the coupling of (+)-4 with CMA isostere $L$ isoleucine, lending strength to the applicability of this strategy for the preparation of COR analogues.

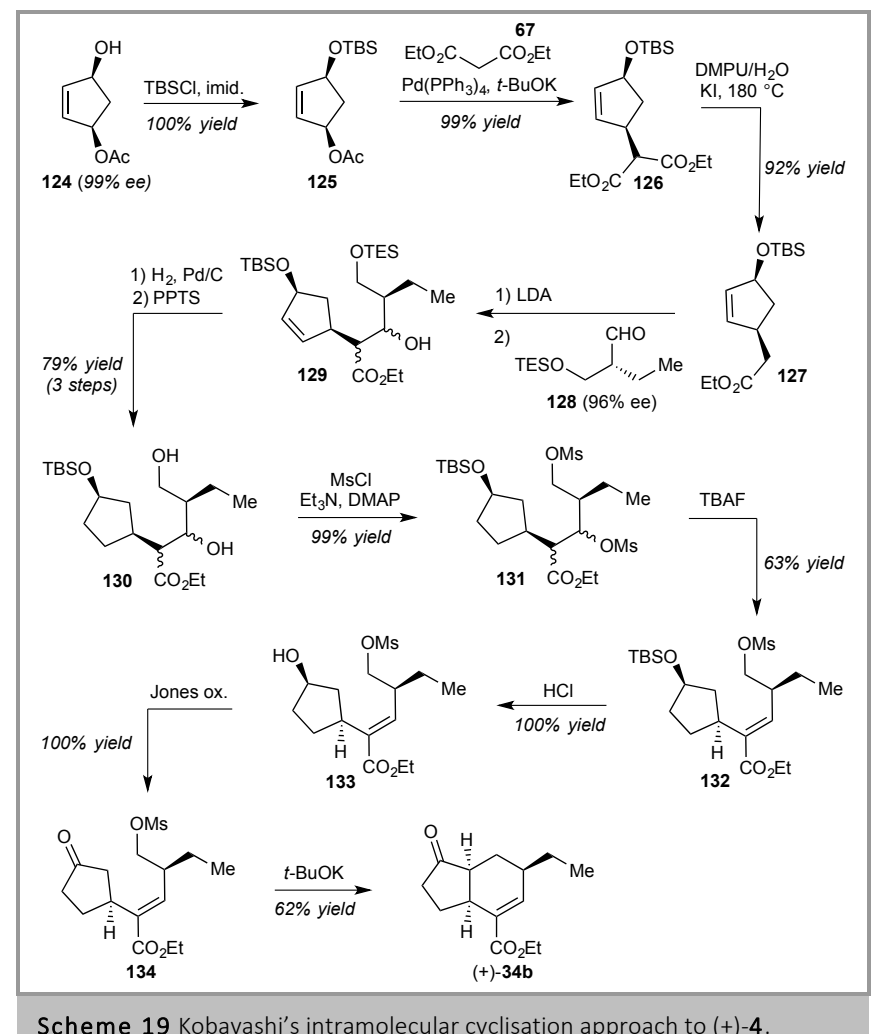

Scheme 19 Kobayashi's intramolecular cyclisation approach to (+)-4.

In a subsequent publication, Kobayashi et al reported a slightly shorter synthetic route, albeit with a reduced overall yield (Scheme 20). ${ }^{56}$

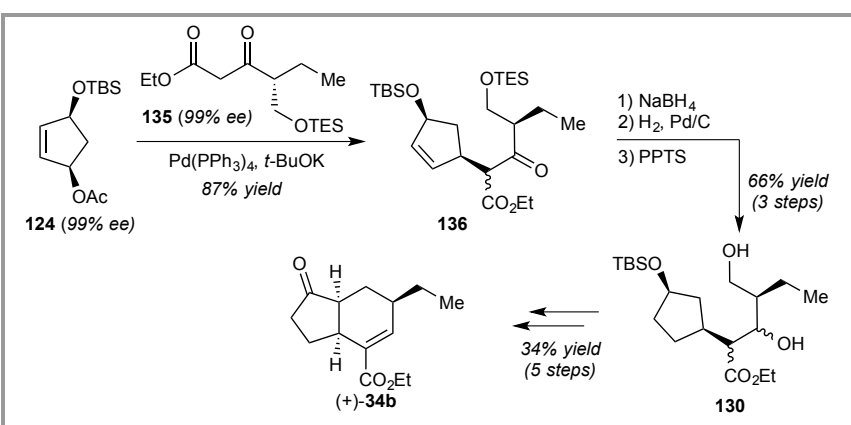

Scheme 20 Kobayashi's shortened route towards (+)-4.

$\beta$-Keto ester 135 was prepared in three steps, using chiral auxiliary-based methodology. ${ }^{55}$ Again, the stereochemistry of the ethyl unit was fixed from the beginning of the synthesis. The authors also showed a range of functionality could be incorporated into the malonate condensation step, which lends the synthetic strategy towards analogue preparation.

Intramolecular cyclization towards the synthesis of $\mathbf{4}$ has also been reported by Taber, who demonstrated the utility of their approach towards enantiopure 5,3- and 6,3-carbocyclic scaffolds by applying the methodology to (+)-4 (Scheme 21).57
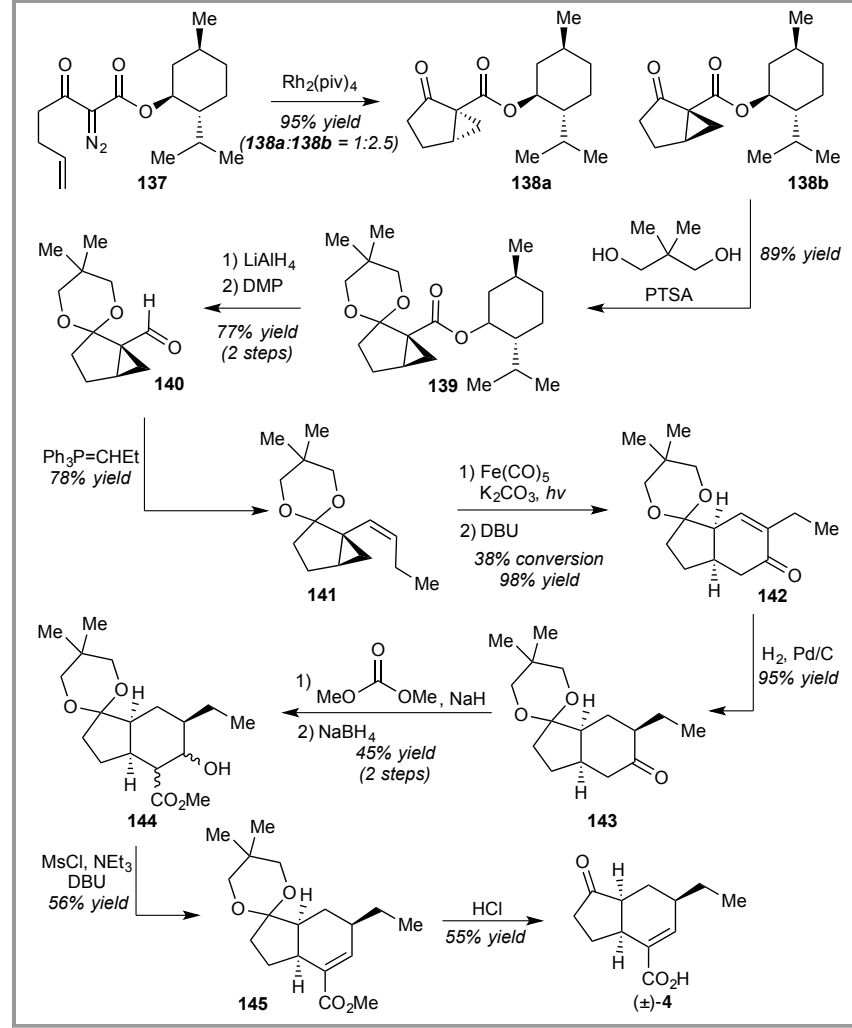

Scheme 21 Taber's menthyl ester-based approach to (+)-4

Under optimized conditions, diastereoselective Rh-catalyzed cyclopropanation of $\mathbf{1 3 7}$ delivered a 2.5:1 mixture of 138a:138b. ${ }^{58}$ 138b was protected as the acetal (139), and reduction of ester to the corresponding alcohol was followed by oxidation, and Wittig reaction to give 141. With respect to analogue synthesis, intermediate $\mathbf{1 4 0}$ is attractive due to the possibility of incorporating various coupling partners. Under buffered reaction conditions to prevent acetal deprotection, a novel Fe-mediated cyclocarbonylation then delivered bicycle 142 in 38\% conversion. On extending the reaction time, the isolated yield began to decrease and, therefore, the reaction was halted at 38\% conversion and the starting material 141 separated and recycled. The authors reported that the kinetic product of the reaction was the $\beta, \gamma$-unsaturated ketone, which was isomerized to the desired enone by the addition of DBU. While the need to separate and recycle the unreacted starting material adds to the synthetic efforts required, the overall high yield of product obtained makes this an attractive key step in the process. Bicycle 142 was then converted to $(+)-\mathbf{4}$ in four steps. Substrate-controlled facially selective hydrogenation of 142 afforded 143 in excellent yield, setting the ethyl stereocentre. Methoxycarbonylation and reduction, was followed by mesylation and elimination in 56\% yield, and, finally, acetal deprotection and ester hydrolysis under acidic conditions provided $(+)-4$ in $55 \%$ yield.

\subsection{Oxy-Cope approaches}

An anionic oxy-Cope rearrangement was used in an early synthesis of ( \pm )-4, communicated by Jung et al (Scheme 22).59,60 Treatment of ketone 146 with lithiated benzofuran delivered alcohol 148, which underwent the oxy-Cope rearrangement to afford 149 in $88 \%$ yield. From 149, the authors accessed ( \pm )-4 in ten steps. Addition of vinyl lithium 150, followed by 
treatment on silica gel afforded ketal 151. Rh-catalyzed reduction, followed by desilylation gave $\mathbf{1 5 2}$ as a mixture of olefins. A second Rh-catalyzed reduction, predominantly from the less hindered convex face, gave $\mathbf{1 5 3}$ as the major product. Removal of the carboxylate protecting group was achieved through ozonolysis, followed by oxidation and hydrolysis. Acid protection through methyl ester formation preceded $\mathrm{POCl}_{3}$ mediated dehydration to afford ( \pm )-29, and, finally, $( \pm)-4$ by acid-mediated hydrolysis in 93\% yield (not shown). The lack of atom economy in this preparation, as well as its overall low yield (1.7\%) limits its attractiveness from a scale up perspective; however, it of synthetic interest as the only example of an oxy-Cope based methodology for the synthesis of $( \pm)-4$.

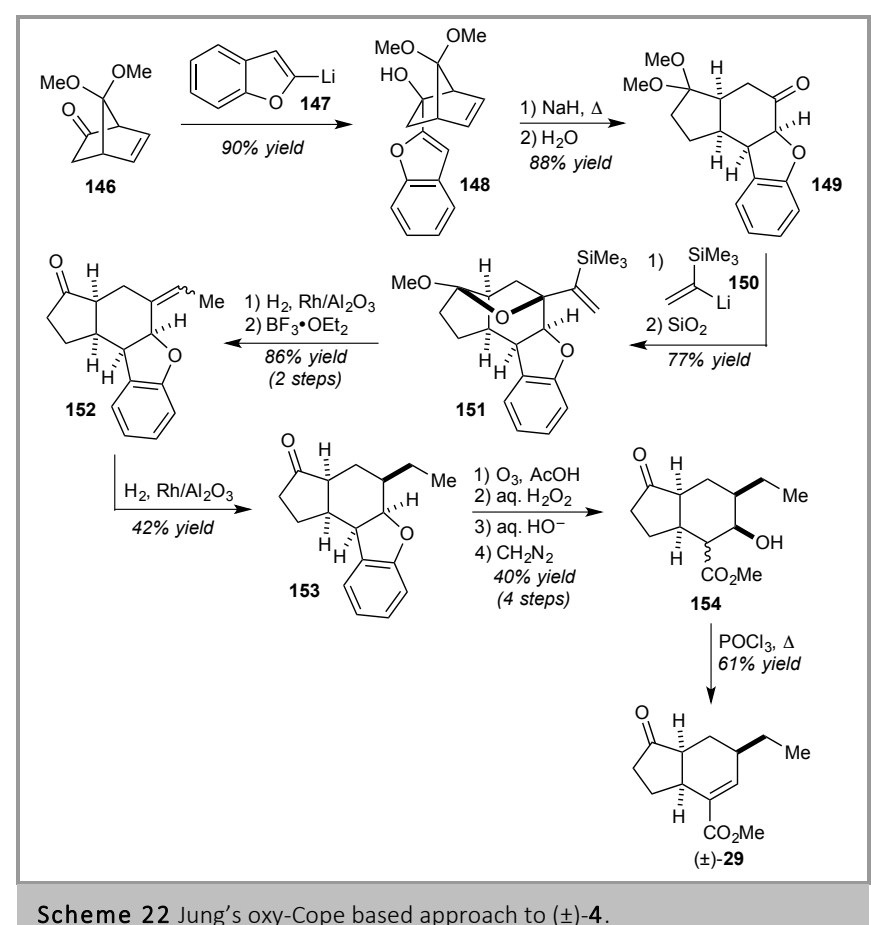

Scheme 22 Jung's oxy-Cope based approach to ( \pm )- 4 .

Overall, a variety of approaches have been utilised in the synthesis of 4 . Diels-Alder reactions have proven to be a popular key step in several syntheses; $23,24,26,29,31,32,34$ however, these often focus on the generation of the same late stage DA precursor. $29,31,32$ Conjugate addition approaches and intramolecular cyclization have also been used several times, providing access to both racemic $35,45,46$ and enantiopure $22,36,37,56,57$ 4. Despite the variety in overall synthetic approaches towards this attractive target, syntheses have typically been long, linear processes, which are ultimately low yielding. As previously intimated, the biological activity of $\mathbf{4}$ make it an attractive starting point for analogue synthesis; however, few of the published synthetic routes offer a practical method for potential diversification, particularly with late stage modifications.

\section{Total synthesis of coronamic acid (CMA, 5)}

\subsection{Total synthesis of CFA: Mapping synthetic strategies}

Natural coronamic acid (5) is present in COR (3) as the (+)$(2 S, 3 S)$-isomer. ${ }^{3}$ Several groups have communicated the synthesis of $(+)-5$, as well as isomers (Figure 5).

Figure 5 (+)-5 and its isomers.

Synthetic efforts have also been directed towards $( \pm)-5$. There exists a multitude of syntheses towards the synthesis of $E$-2alkyl aminocyclopropane carboxylic acids (ACCs) and synthetic pathways can be categorised into seven strategies, grouped according to which ring carbon unit is installed last in the synthesis: $^{61}$ final installation of $\mathrm{C}_{1}, \mathrm{C}_{2}$, or $\mathrm{C}_{3}$. Table 2 shows the reported syntheses of $\mathbf{5}$ in chronological order with their associated key step; Figure 6 shows these key steps in more detail.

\begin{tabular}{|c|c|c|c|c|}
\hline $\begin{array}{l}\text { Author } \\
\text { (Year) }\end{array}$ & $\begin{array}{c}\text { Key step } \\
\text { (No. steps) }\end{array}$ & $\begin{array}{c}\text { Racemic/ } \\
\text { enantiopure }\end{array}$ & $\begin{array}{c}\text { Overall } \\
\text { Yield (\%) }\end{array}$ & Ref. \\
\hline Ichihara (1977) & $C_{1}\left(5^{a}\right)$ & Enantiopure & Unknown & 62 \\
\hline $\begin{array}{c}\text { Stammer } \\
(1983)\end{array}$ & $C_{3}\left(5^{a}\right)$ & Racemic & 18 & 78 \\
\hline Baldwin (1985) & $C_{1}\left(8^{b}\right)$ & Racemic & 23 & 69 \\
\hline Williams (1991) & $C_{2}\left(7^{a}\right)$ & Enantiopure & 51 & 76 \\
\hline $\begin{array}{c}\text { Schollkopf } \\
\text { (1992) }\end{array}$ & $C_{1}\left(5^{b}\right)$ & Enantiopure & 14 & 66 \\
\hline Salaun (1994) & $C_{1}\left(9^{b}\right)$ & Enantiopure & 21 & 65 \\
\hline $\begin{array}{c}\text { Charette } \\
\text { (1995) }\end{array}$ & $C_{2}\left(16^{\mathrm{a}}\right)$ & Enantiopure & 23 & 72 \\
\hline Ichihara (1995) & $C_{1}\left(10^{b}\right)$ & Enantiopure & 30 & 64 \\
\hline Salaun (1995) & $C_{1}\left(3^{b}\right)$ & Racemic & $52^{c}$ & 68 \\
\hline $\begin{array}{c}\text { Yamazaki } \\
\text { (1995) }\end{array}$ & $C_{3}\left(13^{\mathrm{a}}\right)$ & Racemic & 9 & 80 \\
\hline $\begin{array}{c}\text { de Meijere } \\
(2000)\end{array}$ & $C_{3}\left(10^{b}\right)$ & Racemic & 30 & 81 \\
\hline Salaun (2000) & $C_{3}\left(13^{b}\right)$ & Racemic & $32^{c}$ & 82 \\
\hline Cox (2003) & $C_{3}\left(4^{b}\right)$ & Racemic & 17 & 61 \\
\hline Parsons (2004) & $C_{1}\left(7^{b}\right)$ & Racemic & 28 & 71 \\
\hline
\end{tabular}

${ }^{a}$ From a non-commercial starting material. ${ }^{b}$ From commercial starting materials. ${ }^{c}$ Based on an assumed yield from referenced publication. 


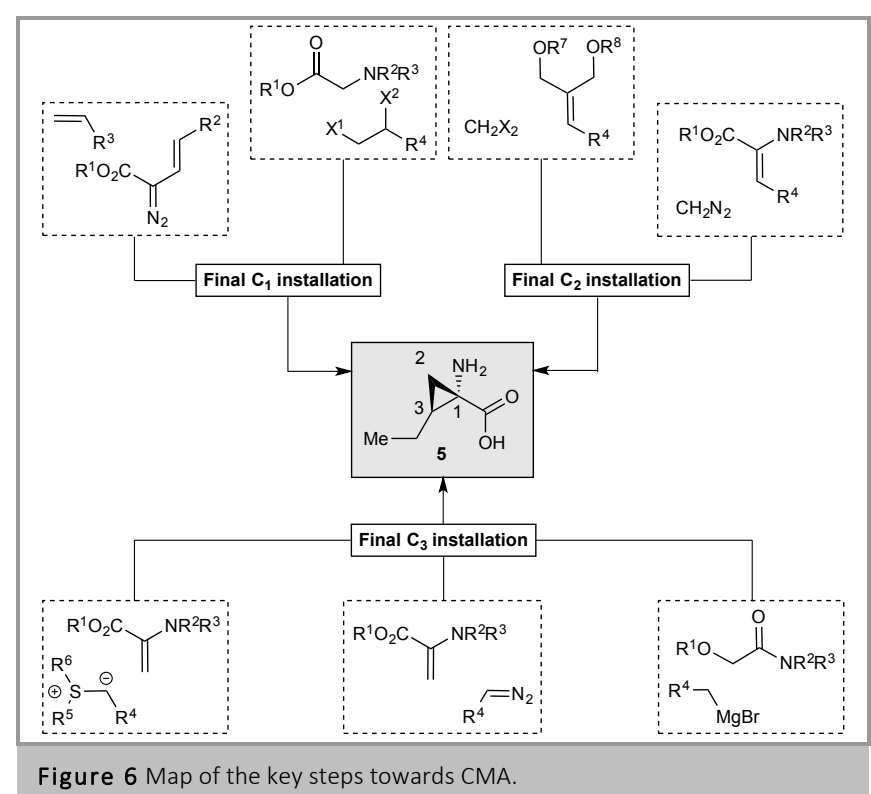

\subsection{Final installation of $\mathrm{C}_{1}$}

Methods for the installation of quaternary $C_{1}$ to complete the cyclopropane ring typically focus on the di-alkylation of glycine analogues. ${ }^{61}$ The first reported synthesis of (+)-5 was communicated by Ichihara et al in the total partial synthesis of $\mathbf{1}$ (Scheme 23). ${ }^{62}$

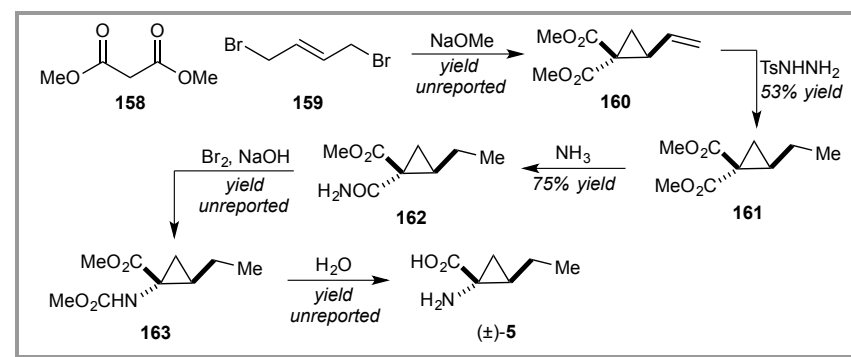

Scheme 23 Ichihara's approach towards (+)-5

The cyclopropane $\mathbf{1 6 0}$ was prepared by the known condensation of trans-1,4-dibromo-2-butene and methyl malonate. ${ }^{63}$ Diimide reduction gave the fully saturated system 161, followed by selective amidation of the least sterically hindered ester to give 162. Hoffmann degradation and hydrolysis then afforded ( \pm )-5. The racemate was resolved by formation of the quinine salt and several fractional recrystallizations were required to obtain enantiomerically pure (+)-5 from this short synthetic sequence.

Ichihara et al later reported the synthesis of (+)-5 through the use of optically pure malic acid $\mathbf{1 6 4}$ as the source of chirality (Scheme 24). ${ }^{64}$

Commercially available $(R)$-malic acid 164 was converted to ketal 165 by reduction of both acids and ketal formation with the resultant 1,2-diol. Tosylation of the free alcohol was followed by conversion to the alkyl iodide, before reduction to afford 166. Hydrolysis of the ketal gave optically active 167. Sequential treatment of $\mathbf{1 6 7}$ with $\mathrm{SOCl}_{2}$ and $\mathrm{RuO}_{4}$ gave access to sulfate ester 168 in quantitative yield. Cyclopropanation was achieved through treatment of $\mathbf{1 6 8}$ with dibenzyl malonate, which proceeded with inversion of stereochemistry at $\mathrm{C}_{3}$.

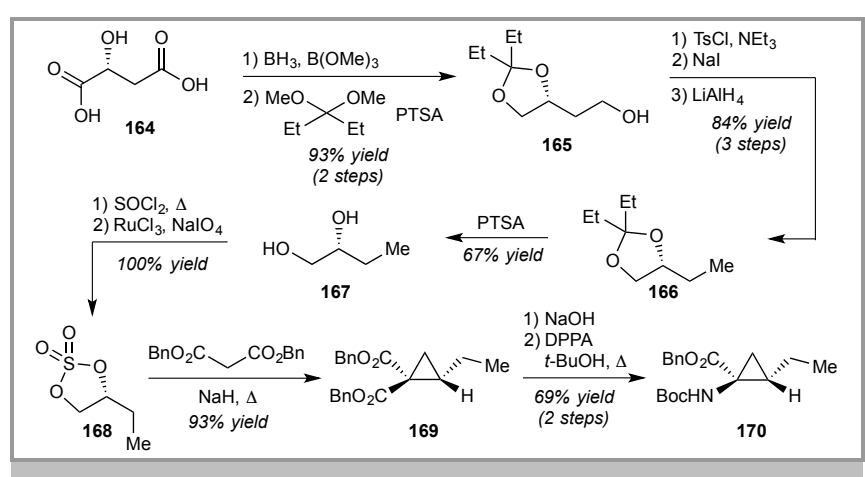

Scheme 24 Ichihara's malic acid based approach towards (+)-5.

Stereoselective hydrolysis of the less sterically hindered ester was followed by Curtius rearrangement to give protected amino acid 170. Deprotection and recrystallization then afforded (+)-5 in $89 \%$ yield (not shown). Notably, this route allowed synthesis of $(+)-5$ on a preparative scale of $11.4 \mathrm{mmol}$ and the authors also demonstrated the utility of the synthetic sequence through the synthesis of all four stereoisomers of $\mathbf{5}$, obtained through use of $(S)$-malic acid. ${ }^{64}$

Salaun et al applied their general method for the construction of $E$-2-alkyl ACCs to the synthesis of (+)-5, using enzymatic resolution (Scheme 25). ${ }^{65}$

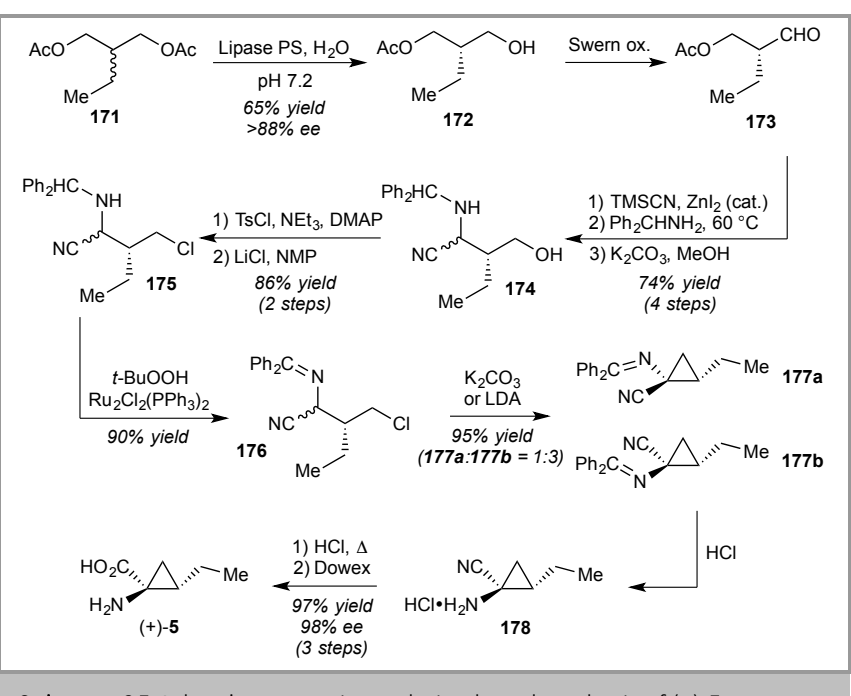

Scheme 25 Salaun's enzymatic resolution based synthesis of (+)-5.

Enzymatic desymmetrization of $\mathbf{1 7 1}$ gave alcohol $\mathbf{1 7 2}$ in moderate yield and high ee. It was reported that higher ee values could be obtained by halting the reaction at $69 \%$ conversion, which accounts for the observed isolated yield of $65 \%$. The authors demonstrated the utility of this intermediate by showing that it can then be converted to various isomers of 5. Towards the synthesis of (+)-5, alcohol $\mathbf{1 7 2}$ was converted to intermediate $\mathbf{1 7 6}$ in seven high yielding steps, with retention of absolute stereochemistry throughout the synthetic procedure. Swern oxidation and a multi-step sequence gave access to intermediate $\mathbf{1 7 4}$ as a mixture of diastereomers. Chemoselective tosylation followed by chlorination gave 175, which was then converted to imine 176. The key step in this route was the diastereoselective cyclization to afford 177 , with the desired diastereomer $\mathbf{1 7 7} \mathbf{b}$ as the major product. Attempted optimization of the cyclization to improve the 
diastereoselectivity was unsuccessful. (+)-5 was then obtained from hydrolysis steps.

Schöllkopf also reported asymmetric synthetic methodology towards the synthesis of $(+)-5 .{ }^{66}$ Based on previous work by Quinkert,67 the publication reports a chiral auxiliary-enabled synthesis (Scheme 26).

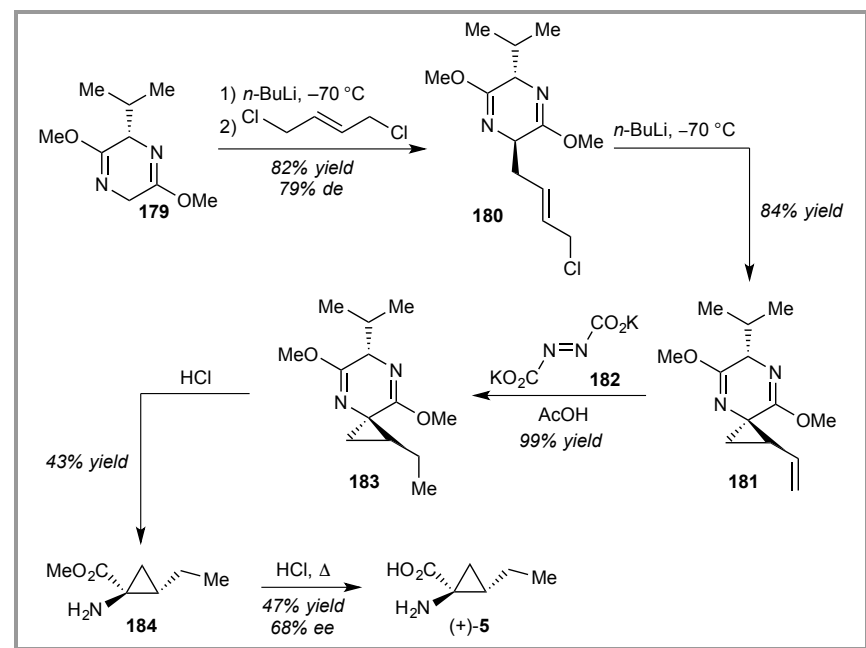

Scheme 26 Schöllkopf's chiral auxiliary based methodology towards (+)-5.

Alkylation of $\mathbf{1 7 9}$ delivered $\mathbf{1 8 0}$ with good diastereocontrol (76\% de). An intramolecular alkylation via $\mathrm{S}_{\mathrm{N}} 2$ ' provided $\mathbf{1 8 1}$ as a mixture of four diastereoisomers, which could be separated by chromatography, thereby allowing access to alternative isomers of $\mathbf{5}$ from a common intermediate. Diimide reduction of $\mathbf{1 8 1}$ to 183 proceeded cleanly, followed by removal of the chiral auxiliary by acid hydrolysis. Further hydrolysis then afforded the free amino acid (+)-5 in reasonable yield of $47 \%$; however, only in a moderate $e e$ of $68 \%$.

In a follow up to their previous asymmetric synthesis, 65 Salaun et al reported a racemic, $\mathrm{Pd}$-catalysed allylation strategy for the synthesis of $\left( \pm\right.$ )-5 (Scheme 27). ${ }^{68}$

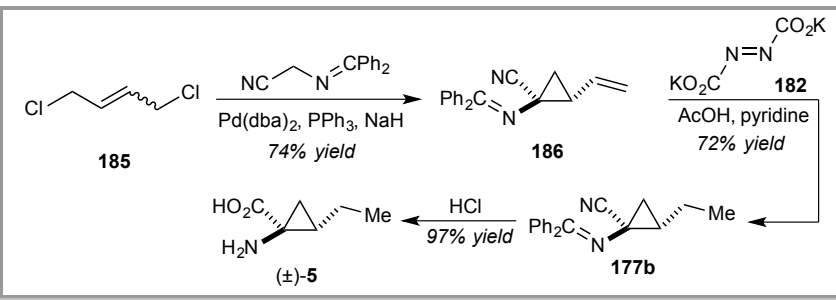

Scheme 27 Salaun's synthesis of $( \pm)-5$ featuring Pd-catalyzed cyclisation.

Di-electrophile 185 generated 186 in high yield and as a single diastereomer via a highly stereoselective cyclization. The vinyl unit of $\mathbf{1 8 6}$ was then reduced to afford intermediate $\mathbf{1 7 7 b}$, as employed in their previous synthesis, ${ }^{66}$ before final hydrolysis to afford ( \pm )-5.

In a report from Baldwin et $a l^{69}( \pm)-5$ was prepared following a short synthetic sequence (Scheme 28).

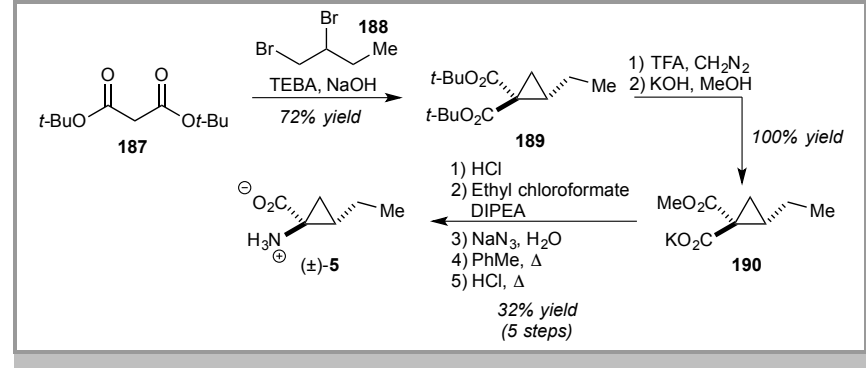

Scheme 28 Baldwin's concise approach to $( \pm)-5$.

Tandem intra-/intermolecular dialkylation of di-tertbutylmalonate 187 using dibromide 188 delivered cyclopropane 189 in good yield. Selective hydrolysis of the least hindered ester, similar to Ichihara, ${ }^{62}$ gave intermediate 190 . The carboxylic acid then underwent Curtius rearrangement, via the acid anhydride, and was then converted to the mixed anhydride, to afford $( \pm)-\mathbf{5}$.

Using methodology developed by Baldwin,70 Parsons et al reported a short synthetic sequence towards $( \pm)-\mathbf{5}$ where the key step was a radical-based 3-exo-trig cyclisation of 191 employing their Mn-mediated methodology (Scheme 29). ${ }^{71}$ The use of biphasic conditions and the phase transfer catalyst benzyltriethylammonium chloride (BTAC) allowed the pentacarbonylmanganese halide to be washed out of the reaction mixture to improve product isolation. Debromination using $n-\mathrm{Bu}_{3} \mathrm{SnH}$ afforded intermediate 193 which was advanced to ( \pm )-5 following the route of Baldwin (not shown). ${ }^{70}$

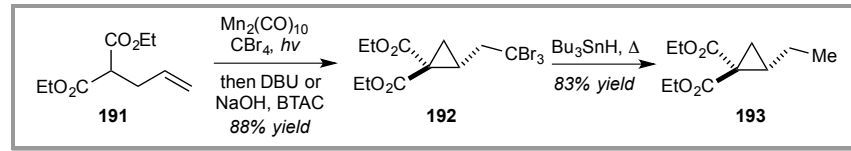

Scheme 29 Parsons' radical based methodology for the synthesis of $( \pm)-5$.

\subsection{Final installation of $\mathrm{C}_{2}$}

Methods for the final installation of $\mathrm{C}_{2}$ typically feature Simmons-Smith cyclopropanation or the 1,3-dipolar cycloaddition of diazo-species. ${ }^{61}$ Charette et al reported a chiral auxiliary-mediated synthesis of 3-methanoamino acids, focusing on $\mathbf{5}$ and its isomers, with the key step being a Simmons-Smith cyclopropanation (Scheme 30). ${ }^{72}$

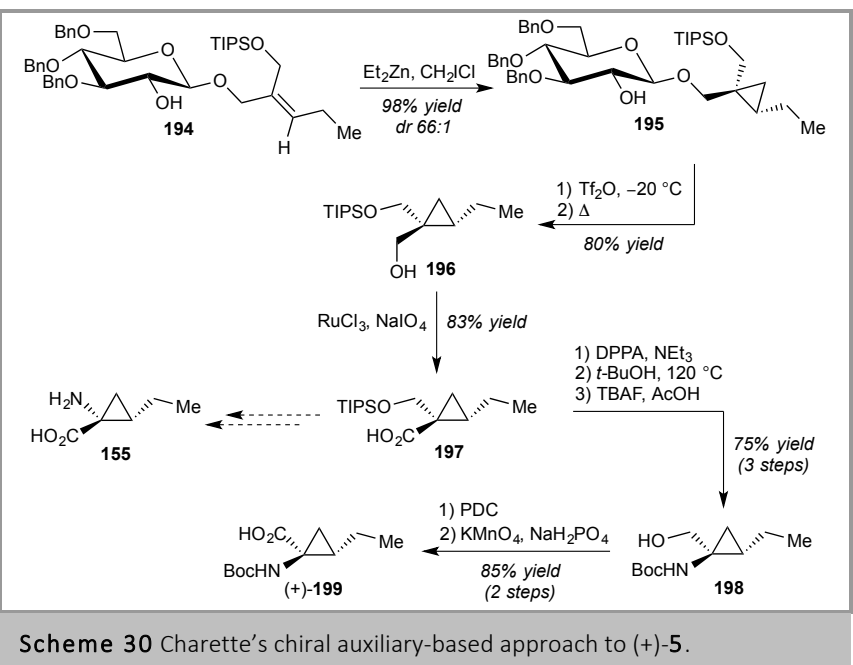


Both the $E$ - and $Z$-glucosides were prepared from a common starting alcohol by changing the order of the synthetic sequence, using methodology previously communicated by the Charette group. ${ }^{73,74}$ Following optimization of the Simmons-Smith reaction, intermediate 195 was obtained in high yield and with good diastereocontrol, setting the absolute stereochemistry of the $\mathrm{C}_{3}$ position. Formation of the triflate facilitated cleavage of the chiral auxillary ${ }^{73}$ and gave cyclopropyl 196 in high yield. Boc-protected (+)-5 was then obtained in six steps. Sharpless oxidation conditions afforded the cyclopropyl acid 197, which could then be differentiated towards both (+)-5, and (+)-allocoronamic acid, 155. To obtain (+)-5, 197 was converted to the corresponding acyl azide, which underwent Curtius rearrangement to install the amine functionality. TBAF deprotection then gave access to 198. The final oxidation reaction to afford Boc-protected (+)-5 (199) was carried out in a two-step process. PDC oxidation allowed access to the corresponding aldehyde, which was then further oxidized to the acid using $\mathrm{KMnO}_{4}$, following the procedure of Masamune. ${ }^{75}$

Williams et al have described the asymmetric synthesis of several ACCs through a phosphonate ester-mediated approach (Scheme 31). ${ }^{76}$ Phosphonate ester 201 was synthesized in two high yielding steps using known chemistry from starting material 200.77 Subsequent Horner-Wadsworth-Emmons olefination of propionaldehyde provided the $E$-alkene, 202, exclusively, which was confirmed by X-ray crystallography. The authors hypothesized that this selectivity was due to the steric repulsion of the Boc protecting group and the aldehyde ethyl unit in the betaine transition state. In order to achieve a facially selective cyclopropanation, a range of conditions was screened for the formation of intermediate 204. Diastereoselective cyclopropanation using sulfonium ylide 203 gave 204 as a single diastereomer in excellent yield. Here, the authors hypothesized that this facial selectivity was the result of $\pi$ stacking between the aryl ring on the ylide and the phenyl substitution on the lactone. Treatment of intermediate 204 under Birch-like conditions gave the Boc-protected amino acid 199, which was hydrolyzed to afford (+)-5. Optical rotation and $\mathrm{X}$-ray analysis proved the retention of absolute configuration throughout the synthetic sequence.

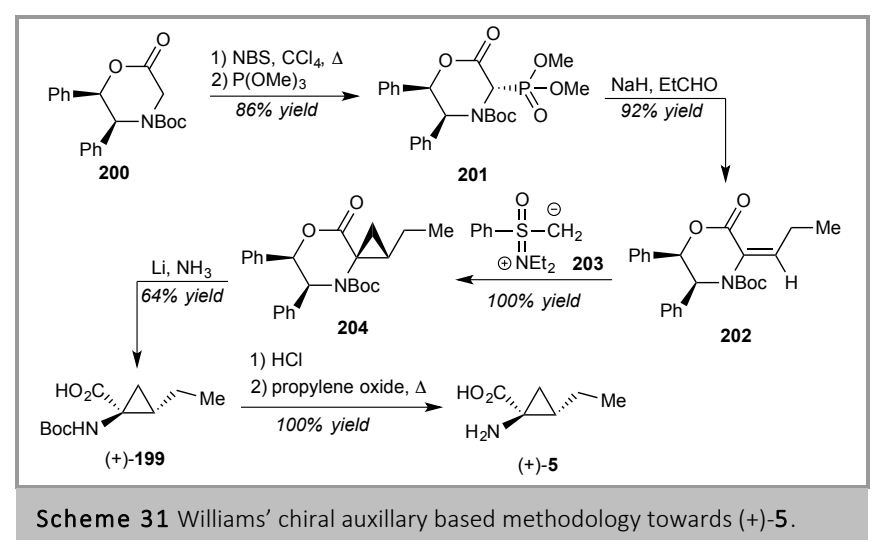

\subsection{Final installation of $\mathrm{C}_{3}$}

Routes which install $\mathrm{C}_{3}$ last typically feature Kulinkovich chemistry or the addition of di-polar species to dehydroamino acids. ${ }^{61}$ Stammer et al developed a synthesis of $( \pm)-\mathbf{5}$, which featured the addition of a diazonium species to a dehydroalanine derivative (Scheme 32)..$^{78}$

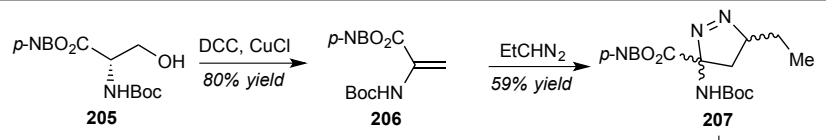

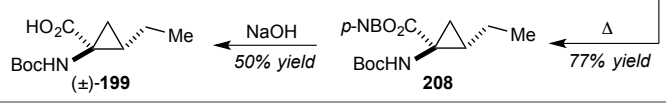

Scheme 32 Stammer's amino acid based approach towards ( \pm )-5.

Dehydration of the serine-derived starting material 205 gave intermediate 206, which could then be treated with a range of diazonium species to afford the corresponding cyclopropyl amino acids via intermediate 207, which underwent pyrolysis upon heating in PhMe to give $\mathbf{2 0 8}$ with the desired relative stereochemistry. Hydrolysis of $\mathbf{2 0 8}$ then afforded Boc protected ( \pm )-199.

Improved handling of the diazo species was reported by Cox et al who applied their methodology for the in situ generation of aryl diazomethanes ${ }^{79}$ to a one-pot diastereoselective synthesis of cyclopropane amino acids. ${ }^{61}$ Aryldiazomethanes were generated in situ from tosylhydrazone derivative 210, which removed the need to handle the reactive diazo species (Scheme 33).

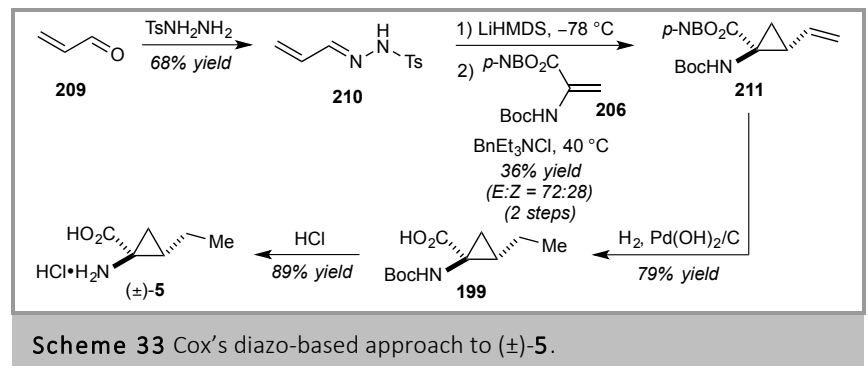

Under phase transfer conditions, cyclopropanation of 206 with $\mathbf{2 1 0}$ delivered $\mathbf{2 1 1}$ as a 72:28 mixture in favour of the desired diastereomer. Reduction of the vinyl unit with concomitant PNB ( $p$-nitrobenzyl) group removal proceeded under hydrogenation conditions, and a final acid-mediated Boc-deprotection afforded ( \pm )-5.

Yamazaki et al have utilised a novel [2+1] cycloaddition, featuring a key Se-enabled 1,2-silicon migration to afford highly functionalised ACCs, which can then be converted to $( \pm)-\mathbf{5}$ (Scheme 34). ${ }^{80}$

Treatment of $\mathbf{2 1 2}$ with 213 in the presence of $\mathrm{ZnBr}_{2}$ gave [2+2]adduct 214 and the desired [2+1]-product 215. The least sterically hindered ester of $\mathbf{2 1 5}$ was reduced to $\mathbf{2 1 6}$ in high yield. Following protection of the alcohol, $\mathbf{2 1 7}$ was oxidized to afford 218. Wittig olefination and diimide reduction provided 219 in good yield. TBAF deprotection afforded alcohol 220, which was advanced to $\mathbf{2 2 1}$ via oxidation and Curtius rearrangement. Global deprotection under acid hydrolysis delivered $( \pm$ ) $-\mathbf{5}$ in $71 \%$ yield (not shown). While synthetically interesting, this synthesis is lengthier and, therefore, lower yielding than other preparations of $( \pm)-\mathbf{5}$. 


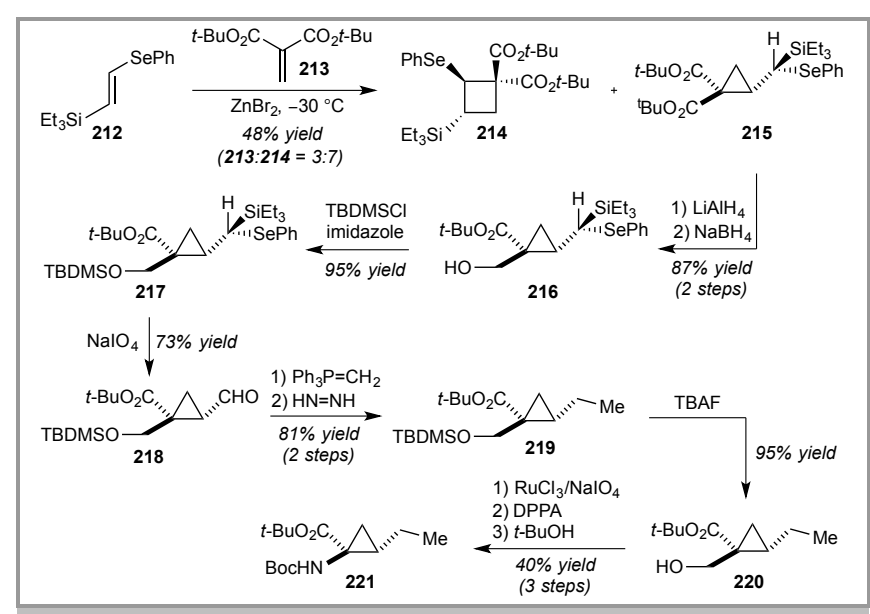

Scheme 34 Yamazaki's cycloaddition based approach to $( \pm)-5$.

de Meijere et al reported the synthesis of $( \pm)-\mathbf{5}$ via Ti-mediated ACC formation (Scheme 35). ${ }^{81}$

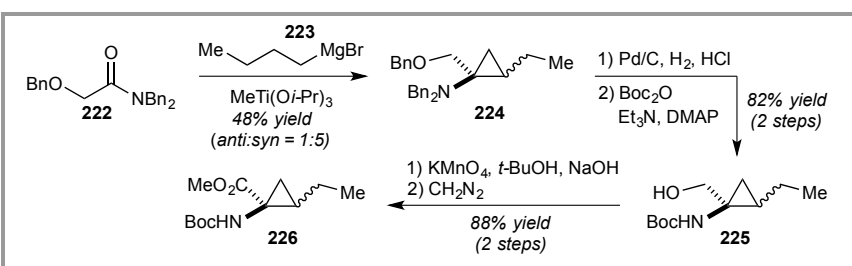

Scheme 35 de Meijere's Kulinkovich-de Meijere based approach to ( \pm )-5.

Amide 222 was prepared in three high yielding steps and on kilogram scale from inexpensive starting materials. The key cyclopropanation was achieved through a Kulinkovich-de Meijere reaction to deliver $\mathbf{2 2 4}$ in moderate yield and favouring the undesired diastereomer, despite attempts to optimise. Benzyl deprotection and subsequent Boc protection provided intermediate 225, on which an analogous oxidation to that communicated by Charette ${ }^{72}$ was attempted. Whereas Charette used conditions developed by Masamune ${ }^{75}$ in a two-step procedure via the aldehyde, Meijere reported a one-step process using $\mathrm{KMnO}_{4}$ to access $\mathbf{2 2 6}$ as a mixture of diastereomers. ${ }^{81}$

Salaun et al also approached ACCs using a Kulinkovich reaction (Scheme 36). ${ }^{82}$ In this case, the cyclopropanated product 228 was obtained in high yield of $92 \%$ and with complete diastereoselectivity through reaction of ester 227 with $n$ BuMgBr. Acylation of the free hydroxyl followed by acetal deprotection gave aldehyde 229. This was then subjected to Knoevanagel condensation under microwave irradiation to give acid 230. Following reduction and mesylate formation, 231 was selectively reduced to afford intermediate $\mathbf{2 3 2}$ in excellent yield. Pd-mediated azide incorporation proceeded with retention of stereochemistry. This was followed by reduction of the azide to the free amine following a known procedure.83 Oxidative cleavage of the alkene unit then afforded $( \pm)-5.83$

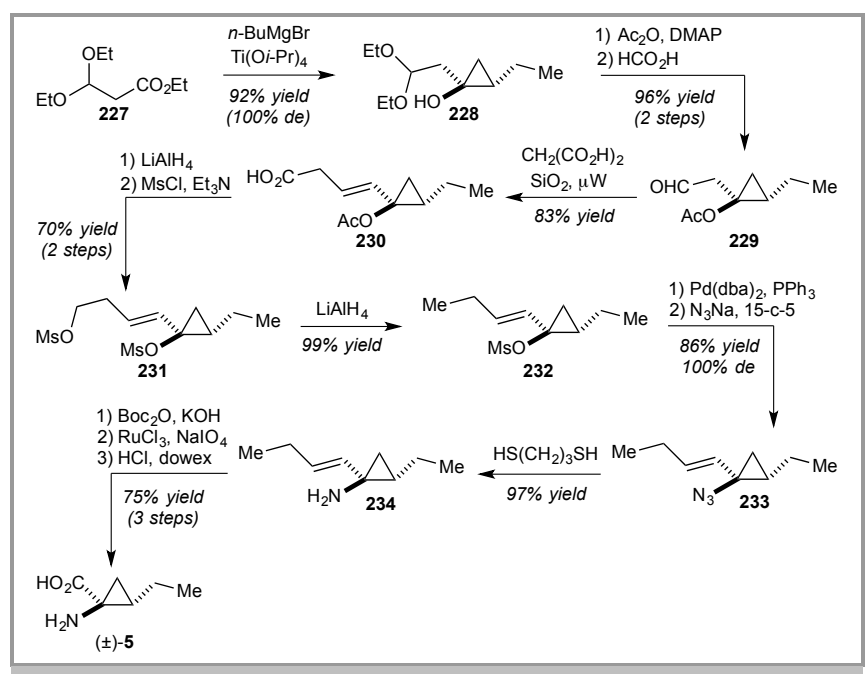

Scheme 36 Salaun's Kulinkovich based approach to $( \pm)-5$.

Overall, a number of well-established methodologies have been leveraged to enable the synthesis of ACCs such as $\mathbf{5}$. These can generally be grouped with regard to overall synthetic strategy, and typically offer short routes to $\mathbf{5}$ and analogues thereof. The most synthetically useful of these approaches allow derivative synthesis from a late stage, common intermediate, which is attractive with respect to generating a structure-activity relationship towards a novel herbicidal agent.

\section{Synthesis of coronatine}

Ueda et al communicated the synthesis of four stereoisomers of 3 , accessed through the condensation of enantiopure (+)-5 and (-)-5 with ( \pm )-4 (Scheme 37). ${ }^{26}$ Boc deprotection of both enantiomers of $\mathbf{5}$ was followed by HBTU-mediated amidation with ( \pm )-4. The free acid was then obtained through hydrogenation of the benzyl protecting group. In both cases, the mixture of diastereoisomers was separated by HPLC. This coupling has also been reported using EDC, again in excellent yield. 36,84

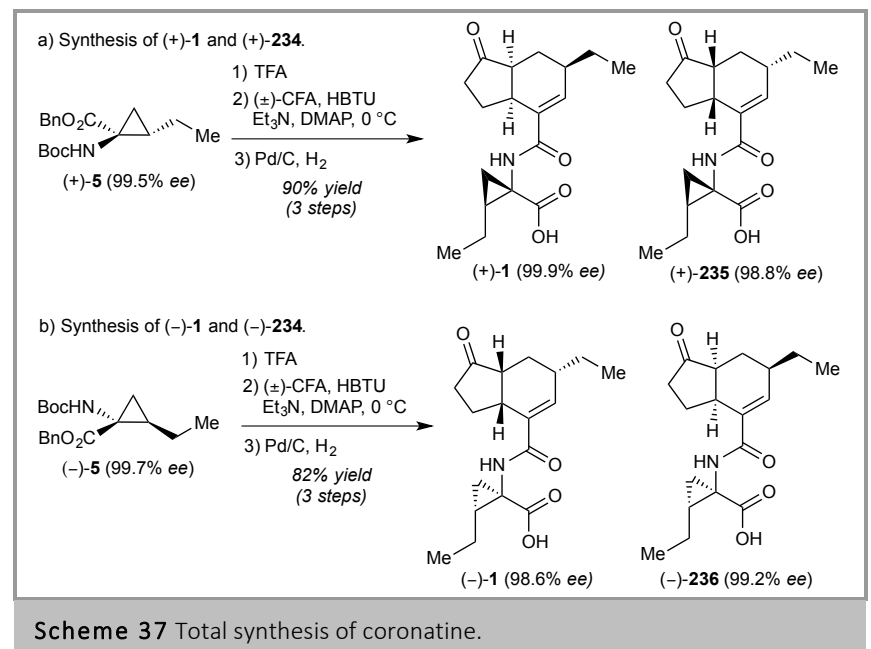

\section{Conclusions}

In conclusion, coronatine (1) presents an attractive synthetic target with significant potential for herbicide generation. The 
natural product can be considered as comprising two structural units, coronafacic acid (4) and coronamic acid (5). ${ }^{2}$ Both these components, particularly 4 , pose a synthetic challenge with respect to amenability to agrochemical discovery programmes. Significant efforts have been made to develop efficient syntheses towards 4, which must take into consideration the stereochemical requirements and ideally be flexible with regards to analogue generation. Varied synthetic routes have been communicated towards the synthesis of $\mathbf{4}$, however there exists a need for a less protracted synthetic sequence, ideally from inexpensive and easily accessed starting materials. Cyclopropane amino acids such as $\mathbf{5}$ have also received considerable attention from a synthetic viewpoint, and several classifications of general methodology amenable to their synthesis are known. ${ }^{61}$ Overall, synthetic efforts towards 4, 5, and ultimately $\mathbf{1}$ have made $\mathbf{1}$ and its analogues a tractable synthetic target for herbicide generation; however, scope exists for the improvement of these approaches, particularly with respect to large scale preparations and the amenability of the route to late stage diversification.

\section{Acknowledgment}

We thank the University of Strathclyde for a studentship (MML) and Syngenta for financial and material support.

\section{References}

(1) Du, M.; Li, X.; Duan, L.; Zhang, M.; Tan, W.; Xu, D.; Li, Z. PLoS One 2014, 9, e97652.

(2) Ichihara, A.; Shiraishi, K.; Sato, H.; Sakamura, S.; Nishiyama, K.; Sakai, R.; Furusaki, A.; Matsumoto, T. J. Am. Chem. Soc. 1977, 99, 636.

(3) Ichihara, A.; Shiraishi, K.; Sakamura, S.; Furusaki, A.; Hashiba, N.; Matsumoto, T. Tetrahedron Lett. 1979, 4, 365.

(4) Fonseca, S.; Chini, A.; Hamberg, M.; Adie, B.; Porzel, A.; Kramell, R.; Miersch, O.; Wasternack, C.; Solano, R. Nat. Chem. Biol. 2009, 5, 344.

(5) Monte, I.; Hamberg, M.; Chini, A.; Gimenez-Ibanez, S.; GarcíaCasado, G.; Porzel, A.; Pazos, F.; Boter, M.; Solano, R. Nat. Chem. Biol. 2014, 10, 671 .

(6) Sheard, L. B.; Tan, X.; Mao, H.; Withers, J.; Ben-Nissan, G.; Hinds, T. R.; Kobayashi, Y.; Hsu, F.-F.; Sharon, M.; Browse, J.; He, S. Y.; Rizo, J.; Howe, G.; Zheng, N. Nature 2010, 468, 400.

(7) Creelman, R.; Mullet, J. E. Annu. Rev. Plant Physiol. Plant Mol. Biol. 1997, 48, 355 .

(8) Krumm, T.; Bandemer, K.; Boland, W. FEBS Lett. 1995, 377, 523.

(9) Yi, H.; Preuss, M. L.; Jez, J. M. Nat. Chem. Biol. 2009, 5, 273.

(10) Rao Uppalapati, S.; Ayoubi, P.; Weng, H.; Palmer, D. A.; Mitchell, R. E.; Jones, W.; Bender, C. L. Plant J. 2005, 42, 201.

(11) Ichihara, A.; Sakamura, S. Toxicon 1983, 187.

(12) Sakai, R. Ann. Phytopathol. Soc. Jpn 1980, 46, 499.

(13) Feys, B. J. F.; Benedetti, C. E.; Penfold, C. N.; Turner, J. G. Plant Cell 1994, 6, 751.

(14) Kenyon, J. S.; Turner, J. G. Plant Physiol. 1992, 100, 219.

(15) Haider, G.; Von Schrader, T.; Füsslein, M.; Blechert, S.; Kutchan, T. M. Biol. Chem. 2000, 381, 741.

(16) Schüler, G.; Mithöfer, A.; Baldwin, I. T.; Berger, S.; Ebel, J.; Santos, J. G.; Herrmann, G.; Hölscher, D.; Kramell, R.; Kutchan, T. M.; Maucher, H.; Schneider, B.; Stenzel, I.; Wasternack, C.; Boland, W. FEBS Lett. 2004, 563, 17.

(17) Okada, M.; Egoshi, S.; Ueda, M. Biosci. Biotechnol. Biochem. 2010, 74, 2092.

(18) Gu, M.; Yan, J.; Bia, Z.; Chen, Y. T.; Lu, W.; Tang, J.; Duan, L.; Xie, D.; Nan, F. J. Bioorg. Med. Chem. 2010, 18, 3012.

(19) Jones, W.; Harvey, D.; Mitchell, R. Food Agric. Immunol. 2002, 14, 301.
(20) Mithöfer, A.; Maitrejean, M.; Boland, W.J. Plant Growth Regul. 2004, $23,170$.

(21) Blechert, S.; Bockelmann, C.; Füßlein, M.; Schrader, T. V.; Stelmach, B.; Niesel, U.; Weiler, E. W. Planta 1999, 207, 470.

(22) Kosaki, Y.; Ogawa, N.; Wang, Q.; Kobayashi, Y. Org. Lett. 2011, 13, 4232.

(23) Ichihara, A.; Kinura, R.; Moriyasu, K.; Sakamura, S. Tetrahedron lett. 1977, 194, 4331.

(24) Liu, H. J.; Llinas-Brunet, M. Can. J. Chem. 1984, 62, 1747.

(25) Sundberg, R. J.; Bukowick, P. A.; Holcombe, F. O. J. Org. Chem. 1967, 32, 2938.

(26) Okada, M.; Ito, S.; Matsubara, A.; Iwakura, I.; Egoshi, S.; Ueda, M. Org. Biomol. Chem. 2009, 7, 3065.

(27) Hale, K. J.; Cai, J. Tetrahedron Lett. 1996, 37, 4233.

(28) Arnold, L. A.; Naasz, R.; Minnaard, A. J.; Feringa, B. L. J. Org. Chem. 2002, 67, 7244 .

(29) Ichihara, A.; Kimura, R.; Yamada, S.; Sakamura, S. J. Am. Chem. Soc. 1980, 102, 6353.

(30) Brannock, K. C.; Bell, A.; Burpitt, R. D.; Kelly, C. A. J. Org. Chem. 1964, 29, 801.

(31) Jung, M. E.; Halweg, K. M. Tetrahedron Lett. 1981, 22, 2735.

(32) Moreau, B.; Ginisty, M.; Alberico, D.; Charette, A. B. J. Org. Chem. 2007, 72, 1235.

(33) Inoue, T.; Liu, J. F.; Buske, D. C.; Abiko, A. J. Org. Chem. 2002, 67, 5250.

(34) Yates, P.; Bhamare, N. K.; Granger, T.; Macas, T. S. Can. J. Chem. 1993, 71, 995.

(35) Nara, S.; Toshima, H.; Ichihara, A. Tetrahedron Lett. 1996, 37, 6745.

(36) Nara, S.; Toshima, H.; Ichihara, A. Tetrahedron 1997, 53, 9509.

(37) Arai, T.; Sasai, H.; Yamaguchi, K.; Shibasaki, M. J. Am. Chem. Soc. 1998, 120, 441.

(38) Arai, T.; Yamada, Y. M. A.; Yamamoto, N.; Sasai, H.; Shibasaki, M. Chem. Eur. J. 1996, 2, 1368.

(39) Haller, A.; Bauer, E. Compt. Rend. 1908, 147, 824.

(40) Mehta, G.; Praveen, M. J. Chem. Soc., Chem. Commun. 1993, 1573.

(41) Chapman, N. B.; Key, J. M.; Toyne, K. J. J. Org. Chem. 1970, 35, 3860.

(42) Schuda, P. F.; Ammon, H. L.; Heimann, M. R.; Bhattacharjee, S. J. Org. Chem. 1982, 47, 3434.

(43) Mehta, G.; Reddy, D. S. Tetrahedron Lett. 1999, 40, 991.

(44) Mehta, G.; Reddy, D. S. J. Chem. Soc. Perkin Trans. 1 2001, 4, 1153.

(45) Sono, M.; Hashimoto, A.; Nakashima, K.; Tori, M. Tetrahedron Lett. 2000, 41, 5115.

(46) Tsuji, J. Pure Appl. Chem. 1981, 53, 2371.

(47) Hoelder, S.; Blechert, S. Synlett 1996, 505.

(48) Kataoka, H.; Yamada, T.; Goto, K.; Tsuji, J. Tetrahedron 1987, 43, 4107.

(49) Nakayama, M.; Ohira, S.; Okamura, Y.; Soga, S. Chem. Lett. 1981, 731.

(50) Szeja, W. Synthesis (Stuttg). 1979, 822.

(51) Bell, H. M.; Vanderslice, C. W.; Spehar, A. J. Org. Chem. 1969, 34, 3923.

(52) Ohira, S. Bull. Chem. Soc. Jpn. 1984, 57, 1902.

(53) Nakayamaand, M.; Ohira, S. Agric. Biol. Chem. 1983, 47, 1689.

(54) Taber, D. F.; Saleh, S. a; Korsmeyer, R. W. J. Org. Chem. 1980, 45, 4699.

(55) Osorio-Lozada, A.; Olivo, H. F. J. Org. Chem. 2009, 74, 1360.

(56) Kinouchi, W.; Kosaki, Y.; Kobayashi, Y. Tetrahedron Lett. 2013, 54, 7017.

(57) Taber, D. F.; Sheth, R. B.; Tian, W. J. Org. Chem. 2009, 74, 2433.

(58) Handa, M.; Takata, A.; Nakao, T.; Kasuga, K.; Mikuriya, M.; Kotera, T. Chem. Lett. 1992, 10, 2085.

(59) Hudspeth, J. P.; Jung, M. E. J. Am. Chem. Soc. 1980, 102, 2463.

(60) Jung, M. E.; Hudspeth, J. P. J. Am. Chem. Soc. 1977, 99, 5508

(61) Adams, L. A.; Aggarwal, V. K.; Bonnert, R. V.; Bressel, B.; Cox, R. J.; Shepherd, J.; De Vicente, J.; Walter, M.; Whittingham, W. G.; Winn, C. L. J. Org. Chem. 2003, 68, 9433.

(62) Ichihara, A. Tetrahedron Lett. 1977, 18, 269.

(63) Murdock, K. C.; Angier, R. B. J. Org. Chem. 1962, 27, 2395.

(64) Toshima, H.; Ichihara, A. Biosci. Biotechnol. Biochem. 1995, 59, 497. 
(65) Gaucher, A.; Ollivier, J.; Marguerite, J.; Paugam, R.; Salaün, J. Can. J. Chem. 1994, 72, 1312.

(66) Groth, U.; Schollkopf, U.; Halfbrodt, W. Liebigs Ann. Chem. 1992, 351.

(67) Quinkert, G.; Schwartz, U.; Stark, H.; Weber, W. D.; Baier, H.; Adam, F.; Duerner, G. Angew. Chem. 1980, 92, 1062.

(68) Gaucher, A.; Dorizon, P.; Ollivier, J.; Salaün, J. Tetrahedron Lett. 1995, 36, 2979.

(69) Adlington, R. M.; Rawlings, B. J.; Baldwin, J. E. Tetrahedron Lett. 1985, 26, 481.

(70) Baldwin, J. E.; Adlington, R. M.; Rawlings, B. J.; Jones, R. H. Tetrahedron Lett. 1985, 26, 485.

(71) Huther, N.; McGrail, P. T.; Parsons, A. F. Eur. J. Org. Chem. 2004, 1740 .

(72) Charette, A. B.; Côté, B. J. Am. Chem. Soc. 1995, 117, 12721.

(73) Charette, A. B.; Côté, B. J. Org. Chem. 1993, 58, 933.

(74) Charette, A. B.; Côté, B. Tetrahedron Lett. 1993, 34, 6833.

(75) Abiko, A.; Roberts, J. C.; Takemasa, T.; Masamune, S. Tetrahedron Lett. 1986, 27, 4537.

(76) Williams, R. M.; Fegley, G. J. J. Am. Chem. Soc. 1991, 113, 8796.

(77) Sinclair, P. J.; Zhai, D.; Reibenspies, J.; Williams, R. M. J. Am. Chem. Soc. 1986, 108, 1103.
(78)

(79)

Suzuki, M.; Gooch, E. E.; Stammer, C. H. Tetrahedron Lett. 1983, 24, 3839.

Aggarwal, V. K.; de Vicente, J.; Bonnert, R. V. Org. Lett. 2001, 3, 2785.

(80) Yamazaki, S.; Kataoka, H.; Yamabe, S. J. Org. Chem. 1999, 64, 2367.

(81) Kordes, M.; Winsel, H.; Meijere, A. De. Eur. J. Org. Chem. 2000, 3235.

(82) Kozyrkov, Y. Y.; Pukin, A.; Kulinkovich, O. G.; Ollivier, J.; Salaün, J. Tetrahedron Lett. 2000, 41, 6399.

(83) Atlan, V.; Racouchot, S.; Rubin, M.; Bremer, C.; Ollivier, J. de Meijere, A.; Salaün, J. Tetrahedron Asymm. 1998, 9, 1131.

(84) Toshima, H.; Nara, S.; Ichihara, A. Biosci. Biotechnol. Biochem. 1997, 61,752 .

\section{Biosketches}

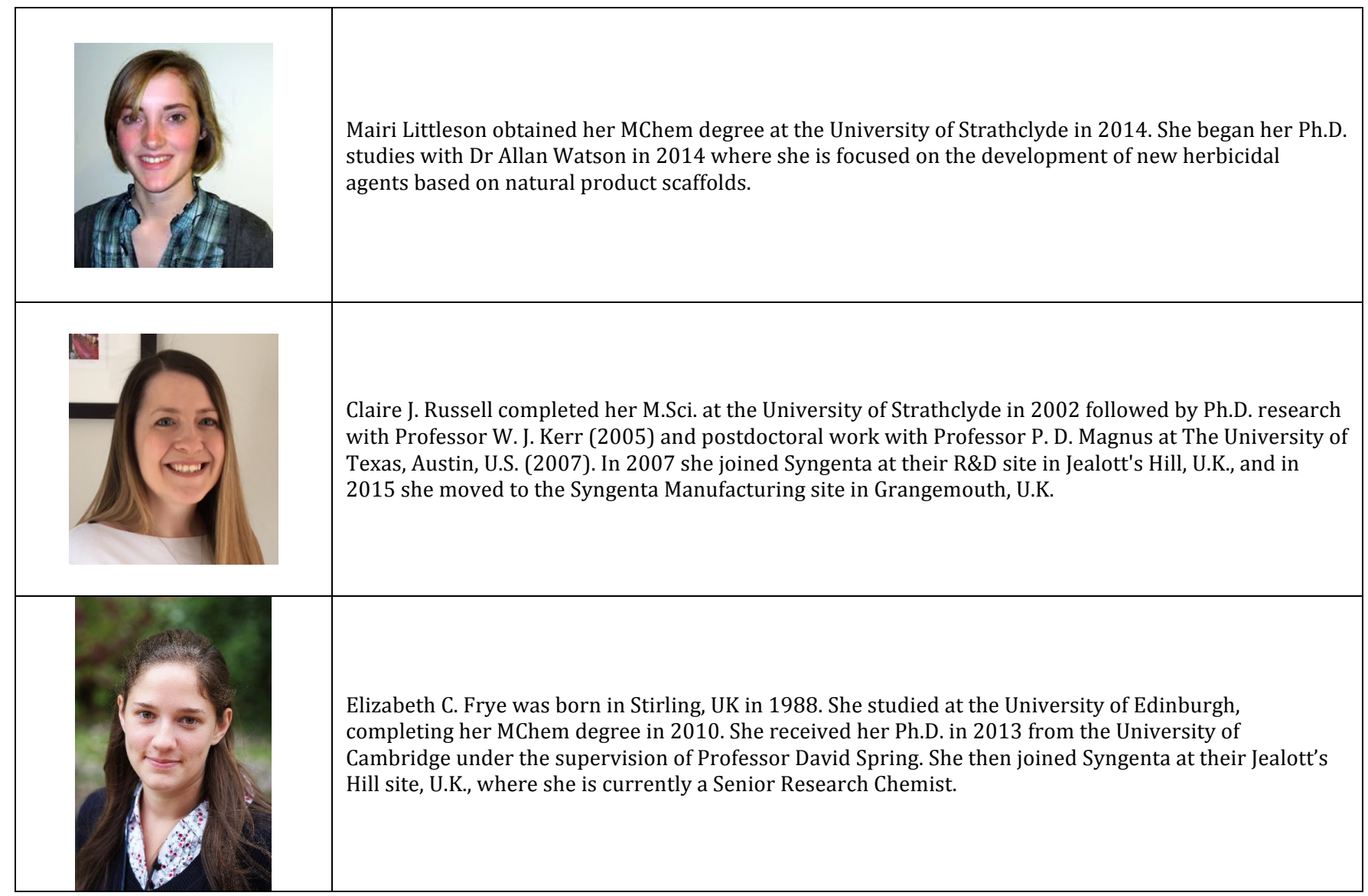




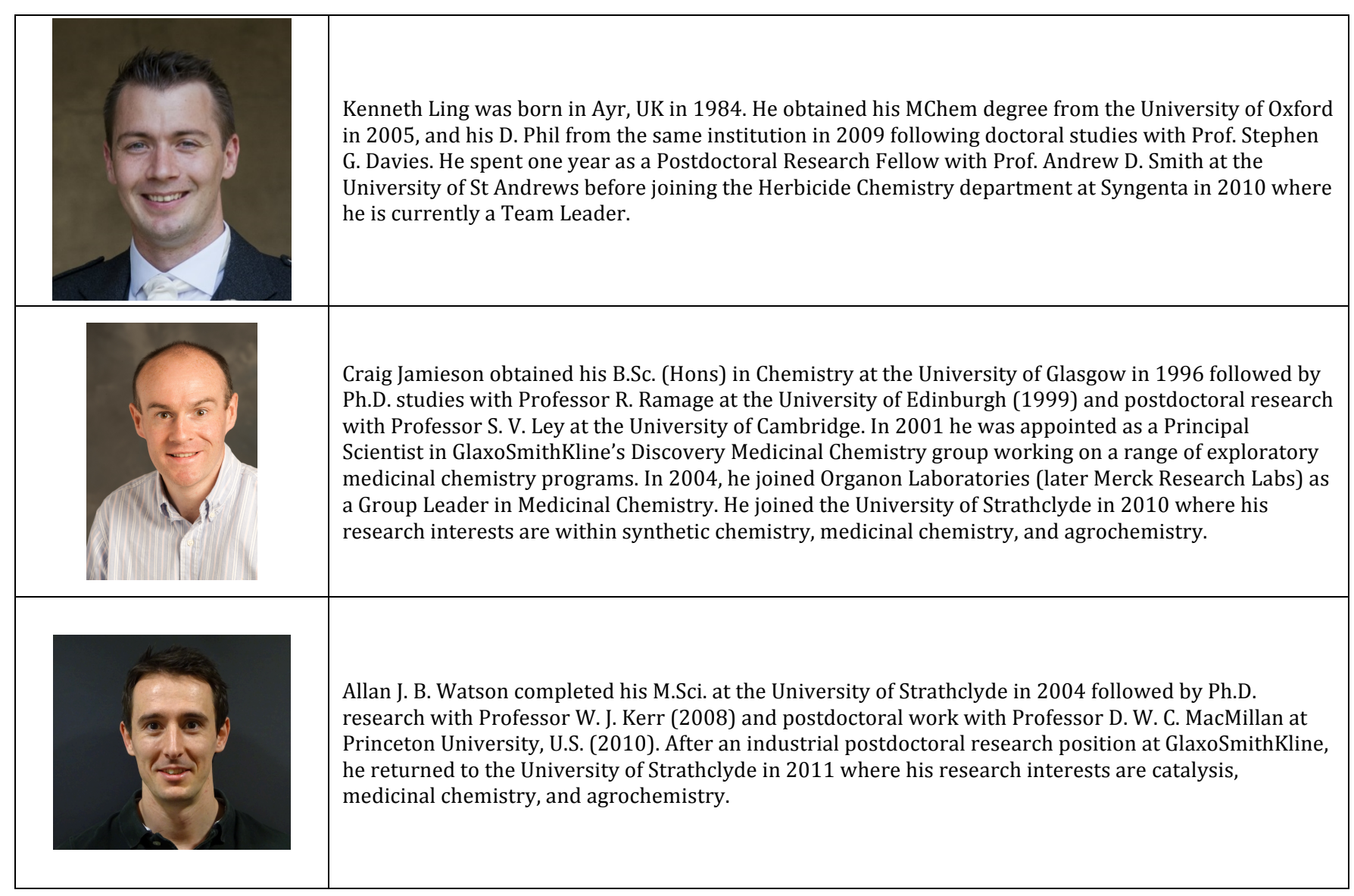

